\title{
The basic regulatory considerations and prospects for conducting bioavailability/ bioequivalence (BA/BE) studies - an overview
}

This article was published in the following Dove Press journal:

Comparative Effectiveness Research

2I March 20II

Number of times this article has been viewed

\author{
Shaik Mastan' \\ Thirunagari Bhavya Latha ${ }^{2}$ \\ Sathe Ajay' \\ 'Cytel Statistical Software and \\ Services Pvt Ltd, Pune, Maharashtra, \\ India; ${ }^{2}$ Business Development, \\ Bioserve Clinical Research Pvt Ltd, \\ Hyderabad, Andhra Pradesh, India
}

\begin{abstract}
Bioavailability (BA) and bioequivalence (BE) studies play a major role in the drug development phase for both new drug products and their generic equivalents, and thus attract considerable attention globally. BE is a strategy to introduce generic equivalents of brand-name drugs (innovator drugs) to lower the cost of medication through proper assessment as directed by the international regulatory authorities. There are several approaches to assess BE and each regulatory authority has its own regulations/guidance for conducting BA/BE studies before approving generic products for marketing in their country. Therefore, a thorough understanding is required of these $\mathrm{BA} / \mathrm{BE}$ concepts and basic regulatory considerations for conducting $\mathrm{BA} / \mathrm{BE}$ studies. This article briefly reviews the BA/BE concepts, approaches, designs, and various basic regulatory considerations and prospects for conducting $\mathrm{BA} / \mathrm{BE}$ studies.
\end{abstract}

Keywords: bioavailability, bioequivalence, generic drugs, regulatory authority, pharmacokinetics, pharmacodynamics

\section{Introduction}

Life expectancy of patients has increased globally during the last three decades due to the new drug discovery (brand-name drugs) as well as generic drug production. It is well known that most health care interventions occur through medication. The rising cost of medication has been contributing to the total overall cost of health care and thus receives considerable attention globally. A major strategy for lowering the cost of medication, and thereby reducing its contribution to total health care costs, has been the introduction of generic equivalents of brand-name drugs (innovator drugs). ${ }^{1}$ This strategy has been effective in reducing total prescription cost by $11 \%$ without sacrificing quality. ${ }^{2}$ Generic drugs have captured more than $65 \%$ of the global market and account for $66 \%$ of prescriptions filled in the United States but for less than $13 \%$ of the cost. ${ }^{3}$

Thus, because of the importance of generic drugs in health care, it is imperative that the pharmaceutical quality, safety, and efficacy of generics should be reliably compared with the corresponding innovator drugs (brand-name drugs). The US Food and Drug Administration (FDA) publishes a list of drug products and equivalents, Approved Drug Products with Therapeutic Equivalence Evaluations, commonly known as the "Orange Book". The FDA's designation of "therapeutic equivalence" indicates that the generic formulation is (among other things) bioequivalent to the innovator formulation and signifies the FDA's expectation that the formulations are likely "to have equivalent clinical effect and no difference in their potential for adverse effects". The assessment of "interchangeability" between the innovator and generic
Correspondence: Shaik Mastan Senior Pharmacokineticist, Cytel Statistical Software and Services Pvt Ltd, (Subsidiary of Cytel Inc., USA), 8th Floor, Siddharth Towers, Kothrud, Pune-4I I 029, Maharashtra, India Tel +9l-982208I869; +9l-9985I76604

Email shkmastan@gmail.com
(C) 201 I Mastan et al, publisher and licensee Dove Medical Press Ltd. This is an Open Access article which permits unrestricted noncommercial use, provided the original work is properly cited. 
products is carried out by a study of "in vivo equivalence" or "bioequivalence". ${ }^{1}$ The steps involved in the development of a potential generic product are briefly described in Figure 1. The pertinent situations in which bioequivalence studies are required include i) when the proposed marketed dosage form is different from that used in pivotal clinical trials; ii) when significant changes are made in the manufacture of the marketed formulation; and iii) when a new generic product is tested against the innovator's marketed product. Based on this background, bioavailability (BA) and bioequivalence (BE) information has been determined to have practical and public health value for pharmaceutical industries, regulatory agencies, patients, and practitioners. To understand the basis of the controversy around innovator drug and generic

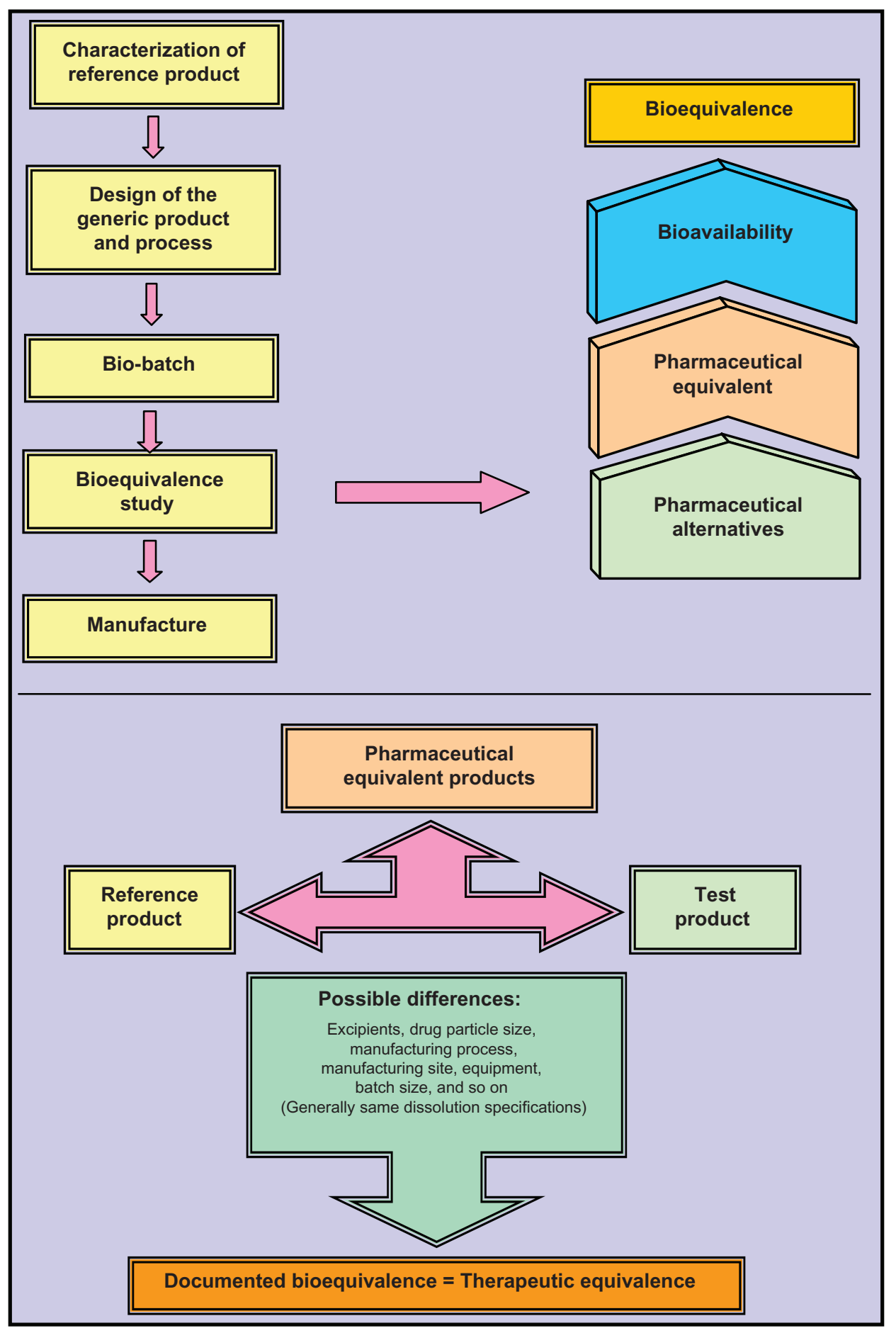

Figure I Critical pathway for the development of a generic drug product. 
interchangeability a thorough understanding of the terms associated with generic drugs is needed.

\section{Definitions $^{5-7}$}

Brand-name drug: A brand-name drug is a drug marketed under a proprietary, trademark-protected name.

Generic drug: A generic drug is the same as a brandname drug in dosage, safety, strength, how it is taken, quality, performance, and intended use.

Pharmaceutical equivalents: Drug products are considered to be pharmaceutical equivalents if they contain the same active ingredient(s), have the same dosage form and route of administration, and are identical in strength or concentration.

Pharmaceutical alternatives: These are drug products that contain the same active moiety but contain different chemical forms such as esters or salts of the active moiety or they may differ from the innovator's product in the dosage form or strength.

Reference listed drug (RLD): A reference listed drug is an approved drug product to which new generic versions are compared to show that they are bioequivalent.

Bioavailability (BA): The rate and extent to which the active ingredient or active moiety is absorbed from a drug product and becomes available at the site of action.

Bioequivalence (BE): The absence of a significant difference in the rate and extent to which the active ingredient or active moiety in pharmaceutical equivalents or pharmaceutical alternatives becomes available at the site of drug action when administered at the same molar dose under similar conditions in an appropriately designed study.

\section{A snapshot on historical perspective}

The concepts of BA and BE have gained considerable importance during the last three decades and have become the cornerstones for the approval of brand-name and generic drugs globally. Consequently regulatory authorities also started developing and formulating regulatory requirements for approval of generic drug products. It is encouraging to know that efforts by regulatory authorities and the scientific community at national as well as international levels are continuing, in order to understand and develop more efficient and scientifically valid approaches to assess $\mathrm{BE}$ of various dosage forms, including some of the complex special dosage forms. Using the $\mathrm{BE}$ as the basis for approving generic drugs was established by the Drug Price Competition and Patent Restoration Act of 1984 (Hatch-Waxman Act). Subsequently various criteria and approaches for conducting and reporting
BE studies for generic products from various regulatory authorities have been progressing. Table 1 presents a brief historical overview of FDA activities with respect to BA/BE studies.

\section{Hatch-Waxman Act ${ }^{10}$}

The Hatch-Waxman Act was an attempt to resolve two major issues: 1) regulatory delays in marketing of pharmaceutical products faced by innovator (also called pioneer or research) drug companies and 2) difficulties generic drug companies had at that time in marketing generic versions of pioneer products following expiry of pertinent patent(s). ${ }^{11,12}$ In practical terms, this Act made the following three important provisions: 1) it provided for the extension of the term of one existing patent for innovator drugs; 2) it made provisions for the marketing of generic versions of patented drugs on the day after patent expiry; and 3) it provided opportunities to challenge the validity of patents issued to innovator drug companies.

\section{Regulatory authorities, regulatory aspects, and international efforts to harmonize approaches to bioequivalence assessment}

Due to significant recognition of the BA/BE concept all over the world, tremendous advancements have been made by the FDA as well as various national, international, and supranational regulatory authorities. In parallel, pharmaceutical industry and academia are also contributing exclusively in the area of assessment of BE. Currently available approaches to determine $\mathrm{BE}$ of generic products are largely standardized due to discussion and consensus reached among various stakeholders at numerous national and international meetings, conferences, and workshops (eg, American Association of Pharmaceutical Scientists, Federation Internationale Pharmaceutique). Thus the currently available excellent scientific and regulatory guidance documents are due to the combined efforts of industry, academia, and regulatory scientists.

Every country now has its own individual regulatory authority as well as regulatory guidance for BA/BE studies, and the magnitude of assessment of $\mathrm{BE}$ of drug product is influenced by the regulatory environment of the respective country of marketing. The regulatory authorities of various countries and international organizations are listed and briefly described in Table 2. In the United States, the FDA approves and grants marketing authorization of generic drugs by applying the regulatory requirements provided in the Code of Federal Regulations (CFR). Table 3 lists 
Table I A brief historical overview of Food and Drug Administration activities with respect to BA/BE studies ${ }^{8,9}$

\begin{tabular}{ll}
\hline Year & Activity \\
\hline 1906 & Food and Drug Act (Wiley Act) \\
1927 & The Bureau of Chemistry is reorganized into two separate entities. Regulatory functions are located in the Food, Drug, and Insecticide \\
& Administration, and nonregulatory research is located in the Bureau of Chemistry and Soils \\
1930 & The name of the Food, Drug, and Insecticide Administration is shortened to Food and Drug Administration (FDA) under an agricultural \\
& appropriations act \\
1935 & US Government begins publication of the Federal Register \\
1938 & The Federal Food, Drug, and Cosmetic (FDC) Act
\end{tabular}

FDA became interested in biological availability of new drugs and a drug bioequivalence study panel was formed by the Office of Technology Assessment (OTA) to understand the chemical and therapeutic equivalent relationship of drug products

On the basis of the recommendations from OTA, the FDA formulated regulations for the submission of bioavailability data. These regulations are currently incorporated in the 2 I st volume of Code of Federal Regulation, Part 320 (2ICFR320)

$75 / 75$ (or 75/75 - 125) rule was originally proposed in the late 1970s as an alternative means of testing the bioequivalence of two formulations of a pharmaceutical agent FDA to approve generic drug products through BA and BE studies process, by assuring the completeness and accuracy of required information and data submissions

- FDA issued guidance on statistical procedures for BE studies

- Generic Drug Enforcement Act

- NLetter on the provision of new information pertaining to new bioequivalence guidelines and refuse-to-file letters

- Two one-sided tests procedure ( $90 \%$ confidence interval statistical approach)

- Letter to all ANDA and AADA applicants about the Generic Drug Enforcement Act of 1992 (GDEA), and the Office of Generic Drugs intention to refuse-to-file incomplete submissions as required by the new law

- Letter to regulated industry notifying interested parties about important detailed information regarding labeling, scale-up, packaging, minor/major amendment criteria, and bioequivalence requirements

Letter on incomplete Abbreviated Applications, Convictions Under GDEA, Multiple Supplements, Annual Reports for Bulk Antibiotics, Batch Size for Transdermal Drugs, Bioequivalence Protocols, Research, Deviations from OGD Policy

1995 SUPAC-IR Immediate-Release Solid Oral Dosage Forms: Scale-Up and Post-Approval Changes: Chemistry, Manufacturing and Controls, In Vitro Dissolution Testing, and In Vivo Bioequivalence Documentation

1997 - Food and Drug Administration Modernization Act (Final)

- Dissolution Testing of Immediate Release Solid Oral Dosage Forms (Final)

- Extended Release Oral Dosage Forms: Development, Evaluation, and Application of In Vitro/ln Vivo Correlations (Final)

- SUPAC-MR: Modified Release Solid Oral Dosage Forms: Scale-Up and Post approval Changes: Chemistry, Manufacturing, and Controls, In Vitro Dissolution Testing, and In Vivo Bioequivalence Documentation

- SUPAC-SS - Nonsterile Semisolid Dosage Forms; Scale-Up and Post approval Changes: Chemistry, Manufacturing, and Controls; In Vitro Release Testing and In Vivo Bioequivalence Documentation

- Good Clinical Practice: Consolidated Guideline (E6)

- General Considerations for Clinical Trials (E8)

1998 - Statistical Principles for Clinical Trials (E9)

- Ethnic Factors in the Acceptability of Foreign Clinical Data

1999 ClinicalTrials.gov is founded to provide the public with updated information on enrollment in federally and privately supported clinical research, thereby expanding patient access to studies of promising therapies.

2000 - Waiver of In Vivo Bioavailability and Bioequivalence Studies for Immediate Release Solid Oral Dosage Forms Based on a Biopharmaceutics Classification System (Final)

- Revising ANDA Labeling Following Revision of the RLD Labeling 
Table I (Continued)

\begin{tabular}{ll}
\hline Year & Activity \\
\hline 2001 & Statistical Approaches to Establishing Bioequivalence (Final) \\
& Bioanalytical Method validation (Final) \\
2002 & Food-Effect Bioavailability and Fed Bioequivalence Studies (Final) \\
2003 & - Bioavailability and Bioequivalence Studies for Orally Administered Drug Products - General Considerations (Revised) \\
& - Bioavailability and Bioequivalence Studies for Nasal Aerosols and Nasal Sprays for Local Action (Draft) \\
& - Bioavailability and Bioequivalence Studies for Orally Administered Drug Products - General Considerations (Revised) \\
& - Statistical Information from the Draft Guidance and Statistical Information for In Vitro Bioequivalence Data (Draft) \\
& Handling and Retention of Bioavailability and Bioequivalence Testing Samples \\
2004 & - Potassium Chloride Modified-Release Tablets and Capsules: In Vivo Bioequivalence and In Vitro Dissolution Testing \\
2005 & - ANDAs: Impurities in Drug Products (Draft) \\
& - Submission of Summary Bioequivalence Data for Abbreviated New Drug Applications (Draft) \\
2009 & - ANDAs: Impurities in Drug Substances (Final) \\
& - Safety Reporting Requirements for INDs (Investigational New Drug Applications) and BA/BE (Bioavailability/Bioequivalence) \\
& - Individual Product Bioequivalence Recommendations - List of Product Bioequivalence Recommendations (Revised)
\end{tabular}

Abbreviations: AADA, abbreviated antibiotic drug application; ANDA, abbreviated new drug application; RLD, reference listed drug; OGD, office of generic drugs.

some of the relevant sections in the CFR related to BA/BE. The magnitude of regulatory influence is often dictated by the availability of resources, expertise, and lack of regulation or its implementation. Thus there is a greater need to harmonize the regulatory environment globally for BE assessment as far as practicable so that the drug product marketed in different parts and regions of the world would have optimum drug product quality in terms of interchangeability. In the recent years, some significant progress has been made towards harmonization; in addition some regulatory authorities are also in the process of cooperating with their counterparts from other countries to harmonize the regulatory requirements while streamlining their own regulatory requirements.

Tremendous work towards harmonization was initiated and completed by some organizations, especially the International Conference on Harmonization (ICH) and the World Health Organization (WHO). ICH is a consortium of regulatory authorities from Europe, Japan, and the United States which focused primarily on developing guidelines for standardizing and harmonizing the regulatory requirements, mainly for aspects of chemistry and manufacturing control, safety, and efficacy of new drug product quality. In addition, it developed specific documents for the content and format of drug product dossiers. It has not yet focused on harmonizing the requirements for approval of generic equivalents. On the other hand, the WHO has made remarkable progress specifically in developing international consensus on the regulatory requirements for assessing $\mathrm{BE}$ for marketing authorization of multisource pharmaceutical products for interchangeability, selection of comparator product for BE assessment, and other related regulatory documents. Apart from the ICH and WHO other European and Asian organizations (national and international) are actively involved in harmonization efforts for assessing of BE and improving the quality of pharmaceutical products globally.

\section{Assessment of bioequivalence ${ }^{14-25}$}

The assessment of BE of different drug products is based on the fundamental assumption that two products are equivalent when the rate and extent of absorption of the test/generic drug does not show a significant difference from the rate and extent of absorption of the reference/brand drug under similar experimental conditions as defined. As per the different regulatory authorities, BE studies are generally classified as:

1. Pharmacokinetic endpoint studies.

2. Pharmacodynamic endpoint studies.

3. Clinical endpoint studies.

4. In vitro endpoint studies.

The general descending order of preference of these studies includes pharmacokinetic, pharmacodynamic, clinical, and in vitro studies. ${ }^{14}$

\section{Pharmacokinetic endpoint studies}

These studies are most widely preferred to assess BE for drug products, where drug level can be determined in an easily accessible biological fluid (such as plasma, blood, urine) and drug level is correlated with the clinical effect. The statutory definition of $\mathrm{BA}$ and $\mathrm{BE}$, expressed in rate and extent of absorption of the active moiety or ingredient to the site of action, emphasizes the use of pharmacokinetic 
Table 2 A brief description of regulatory authorities of various countries and international organizations

\begin{tabular}{|c|c|c|}
\hline Country & Regulatory authority & Website \\
\hline India & $\begin{array}{l}\text { Central Drugs Standard Control Organization } \\
\text { (CDSCO) }\end{array}$ & http://cdsco.nic.in/ \\
\hline Unites States & US Food and Drug Administration (FDA) & http://www.fda.gov/ \\
\hline Europe & European Medicines Agency (EMEA) & http://www.ema.europa.eu/ \\
\hline \multirow[t]{2}{*}{ United Kingdom } & Medicines and Health care products Regulatory & http://www.mhra.gov.uk/ \\
\hline & Agency (MHRA) & \\
\hline Canada & Health Canada & http://www.hc-sc.gc.ca/ \\
\hline South Africa & Medicines Control Council (MCC) & http://www.mccza.com/ \\
\hline Australia & Therapeutic Goods Administration (TGA) & http://www.tga.gov.au/ \\
\hline Korea & Korea Food and Drug Administration (K-FDA) & http://www.kfda.go.kr/ \\
\hline Mexico & Ministry of Health & http://www.salud.gob.mx/ \\
\hline Japan & Pharmaceuticals and Medical Devices Agency (PMDA) & http://www.pmda.go.jp/ \\
\hline \multirow[t]{2}{*}{ People's Republic of China } & National Institute for the Control of & http://www.nicpbp.org.cn/cmsweb/ \\
\hline & Pharmaceutical and Biological Products & \\
\hline \multirow[t]{2}{*}{ New Zealand } & Medicines and Medical Devices Safety & http://www.medsafe.govt.nz/ \\
\hline & Authority (MEDSAFE) & \\
\hline Malaysia & National Pharmaceutical Control Bureau & http://portal.bpfk.gov.my/ \\
\hline Hong Kong & Department of Health & http://www.dh.gov.hk/ \\
\hline Fiji & Ministry of Health & http://www.health.gov.fj/ \\
\hline Indonesia & Ministry of Health & http://www.depkes.go.id/ \\
\hline Singapore & Health Sciences Authority (HAS) & http://www.hsa.gov.sg \\
\hline Sri Lanka & Ministry of Health & http://www.health.gov.lk/ \\
\hline \multirow{2}{*}{ Armenia } & Scientific Center of Drug and Medical & http://www.pharm.am/ \\
\hline & Technologies Expertise (SCDMTE) & \\
\hline Taiwan & Department of Health (DOH) & http://www.doh.gov.tw/ \\
\hline Belgium & Pharmaceutical Inspectorate & http://afigp.fgov.be/ \\
\hline Bulgaria & Drug Agency & http://www.bda.bg/ \\
\hline Czech Republic & State Institute for Drug Control & http://www.sukl.cz/ \\
\hline Finland & National Agency for Medicines & http://www.nam.fi/ \\
\hline \multirow{2}{*}{ France } & Agence Francaise de Securite Sanitaire des & http://www.afssaps.fr/ \\
\hline & Produits de Sante (AFSSAPS) & \\
\hline Germany & Federal Institute for Drugs and Medical Devices & http://www.bfarm.de/ \\
\hline Greece & National Organization for Medicines & http://www.eof.gr/ \\
\hline Iceland & Icelandic Medicines Agency (IMA) & http://www.imca.is/ \\
\hline Ireland & Medicines Board & http://www.imb.ie/ \\
\hline Italy & National Institute of Health & http://www.iss.it/ \\
\hline Netherlands & Medicines Evaluation Board & http://www.cbg-meb.nl/ \\
\hline Norway & Norwegian Medicines Agency & http://www.legemiddelverket.no/ \\
\hline Poland & Drug Institute & \\
\hline Spain & Spanish Drug Agency & http://www.msc.es/ \\
\hline Sweden & Medical Products Agency & \\
\hline Switzerland & Swiss Agency for Therapeutic Products & http://www.swissmedic.ch/ \\
\hline Israel & Ministry of Health & http://www.health.gov.il/ \\
\hline Saudi Arabia & Ministry of Health & http://www.moh.gov.sa/ \\
\hline United Arab Emirates & Federal Department of Pharmacies & http://www.uae.gov.ae/ \\
\hline Kenya & Ministry of Health & \\
\hline Namibia & Ministry of Health and Social Services & http://www.healthforall.net/grnmhss/ \\
\hline Tanzania & Ministry of Health & http://www.tanzania.go.tz/ \\
\hline Zimbabwe & Ministry of Health and Child Welfare & http://www.gta.gov.zw/health.html \\
\hline Brazil & National Health Surveillance Agency (ANVISA) & http://www.anvisa.gov.br/ \\
\hline \multirow[t]{2}{*}{ Colombia } & Instituto Nacional de Vigilancia de Medicamentos & http://web.invima.gov.co/ \\
\hline & Y Alimentos (INVIMA) & \\
\hline \multicolumn{3}{|l|}{ International organizations } \\
\hline International Conference on Harmonisation (ICH) & & http://www.ich.org/ \\
\hline World Health Organization (WHO) & & http://www.who.int/ \\
\hline \multirow[t]{2}{*}{ Global GMP Harmonization by Japan } & & http://www.nihs.go.jp/drug/section3/ \\
\hline & & hiyama0705 |8-3.pdf \\
\hline European Union (European & & http://www.ema.europa.eu/ \\
\hline \multicolumn{3}{|l|}{ Commission and EMEA) } \\
\hline Global Harmonization Task Force (GHTF) & & http://www.ghtf.org/ \\
\hline Association of Southeast Asian Nations Consultative & & http://www.aseansec.org/ \\
\hline Committee for Standards and Quality ASEAN & & \\
\hline
\end{tabular}

6 submit your manuscript $\mid$ www.dovepress.com $\quad$ Comparative Effectiveness Research 201 I:I


Table 3 Some of relevant sections in the Code of Federal Regulations related to BA/BE studies ${ }^{13}$

\begin{tabular}{|c|c|}
\hline 2 ICFR section & Type of provision/information \\
\hline 2 ICFR 3I4.94(a)(9) & $\begin{array}{l}\text { Chemistry, manufacturing, and controls; permitted changes in inactive ingredients for parenteral, otic, } \\
\text { ophthalmic, and topical drug products }\end{array}$ \\
\hline 2 ICFR 320.1 & Definitions of bioavailability, pharmaceutical equivalents, pharmaceutical alternatives, and bioequivalence \\
\hline 2 ICFR 320.21 & Regulatory requirements related to submission of in vivo bioavailability and bioequivalence data \\
\hline 2 ICFR 320.22 & Criteria for waiver of evidence of in vivo bioavailability or bioequivalence data \\
\hline 2 ICFR 320.23 & Basis for measuring in vivo bioavailability or demonstrating bioequivalence \\
\hline 2 ICFR 320.24 & Types of evidence to measure bioavailability or establish bioequivalence \\
\hline 2 ICFR 320.25 & Guidelines for the conduct of an in vivo bioavailability study \\
\hline 2 ICFR 320.26 & Guidelines on the design of a single dose in vivo bioavailability or bioequivalence study \\
\hline 2 ICFR 320.27 & Guidelines on the design of a multiple-dose in vivo bioavailability study \\
\hline 2 ICFR 320.28 & Correlation of bioavailability with an acute pharmacological effect or clinical evidence \\
\hline 2 ICFR 320.29 & Analytical methods for an in vivo bioavailability or bioequivalence study \\
\hline 2 ICFR 320.30 & Inquiries regarding bioavailability and bioequivalence requirements and review of protocols by the FDA \\
\hline 2 ICFR 320.32 & Procedures for establishing or amending a bioequivalence requirement \\
\hline 2 ICFR 320.33 & Criteria and evidence to assess actual or potential bioequivalence problems \\
\hline 2ICFR 320.36 & Requirements for maintenance of records of bioequivalence testing \\
\hline 2 ICFR 320.38 & Retention of bioavailability samples \\
\hline 2ICFR 320.63 & Retention of bioequivalence samples \\
\hline
\end{tabular}

measures to indicate release of the drug substance from the drug product with absorption into the systemic circulation. Regulatory guidance recommends that measures of systemic exposure be used to reflect clinically important differences between test and reference products in BA and BE studies. ${ }^{14}$ These measures include i) total exposure $\left(\mathrm{AUC}_{0-\mathrm{t}}\right.$ or $\mathrm{AUC}_{0-\infty}$ for single-dose studies and $\mathrm{AUC}_{0-\tau}$ for steady-state studies), ii) peak exposure $\left(\mathrm{C}_{\max }\right)$, and iii) early exposure (partial $\mathrm{AUC}$ to peak time of the reference product for an immediate-release drug product). Reliance on systemic exposure measures will reflect comparable rate and extent of absorption, which, in turn, will achieve the underlying goal of assuring comparable therapeutic effects. Single dose studies to document BE were preferred because they are generally more sensitive in assessing in vivo release of the drug substance from the drug product when compared to multiple dose studies. Table 4 describes the general pharmacokinetic parameters (primary and secondary) for single-dose, multiple-dose, and urinary data.

The following are the circumstances that demand multiple-dose study/steady state pharmacokinetics: ${ }^{15,16,18,21-26}$

- Dose- or time-dependent pharmacokinetics.

- For modified-release products for which the fluctuation in plasma concentration over a dosage interval at steady state needs to be assessed.

- If problems of sensitivity preclude sufficiently precise plasma concentration measurements after single-dose administration.

- If the intra-individual variability in the plasma concentration or disposition precludes the possibility of demonstrating BE in a reasonably sized single-dose study and this variability is reduced at steady state.

- When a single-dose study cannot be conducted in healthy volunteers due to tolerability reasons, and a single-dose study is not feasible in patients.

- If the medicine has a long terminal elimination half-life, and blood concentrations after a single dose cannot be followed for a sufficient time.

- For those medicines that induce their own metabolism or show large intra-individual variability.

- For combination products for which the ratio of plasma concentration of the individual substances is important.

- If the medicine is likely to accumulate in the body.

- For enteric coated preparations in which the coating is innovative.

Under normal circumstances, blood should be the biological fluid sampled to measure drug concentrations. Most drugs may be measured in serum or plasma; however, in some drugs, whole blood (eg, tacrolimus) may be more appropriate for analysis. If the blood concentrations are too minute to be detected and a substantial amount $(>40 \%)$ of the drug is eliminated unchanged in the urine, the urine may serve as the biological fluid to be sampled (eg, alendronic acid)..$^{21,22,26}$

\section{Pharmacodynamic endpoint studies ${ }^{1,15}$}

Pharmacokinetic studies measure systemic exposure but are generally inappropriate to document local delivery BA and BE. In such cases, BA may be measured, and BE may be established, based on a pharmacodynamic study, providing an appropriate 
Table 4 Brief description of the pharmacokinetic parameters used for BA/BE studies

\begin{tabular}{lll}
\hline Study type & Primary pharmacokinetic parameters & Secondary pharmacokinetic parameters \\
\hline Single dose & $\mathrm{C}_{\max }, \mathrm{AUC}_{0-\mathrm{t}}, \mathrm{AUC}_{0-\infty}$ & $\mathrm{T}_{\max }, \mathrm{AUC} \%$ extrapolation, MRT, $\mathrm{K}_{\mathrm{el}}$, and $\mathrm{T}_{1 / 2}$ \\
Steady state & $\mathrm{C}_{\max (\mathrm{ss})}, \mathrm{C}_{\min (\mathrm{ss})}, \mathrm{AUC}_{0-\tau}, \mathrm{T}_{\min (\mathrm{ss})}, \mathrm{T}_{\max (\mathrm{ss})}, \mathrm{C}_{\text {avg }}, \%$ swing, \% fluctuation \\
Urinary based & $\mathrm{Ae}_{(0-\mathrm{t})}, \mathrm{Ae}_{(0-\infty)}, \mathrm{R}_{\max }$ & $\mathrm{T}_{\text {lag }}$ \\
\hline
\end{tabular}

Notes: $C_{\max }$, Maximum plasma concentration; $C_{\min }$, Minimum plasma concentration; $C_{\max (s s)}$, Maximum plasma concentration at steady-state; $C_{\min (s)}$, Minimum plasma concentration at steady-state; $C_{\text {avg }}$, Average plasma concentration; $T_{\max }$, Time to $C_{\max }, A C_{0-t}$, Area under the plasma/serum/blood concentration-time curve from time zero to time $t$ where $t$ is the last time point with measurable concentration; $A U C_{0-\infty}$, Area under the plasma/serum/blood concentration-time curve from time zero to time infinity; $\mathrm{AUC}_{0-\tau}$, $\mathrm{AUC}$ during a dosage interval at steady state; MRT, Mean residence time; $\mathrm{Ae}_{(0-t)}$, Cumulative urinary excretion from pharmaceutical product administration until time $\mathrm{t} ; \mathrm{Ae}_{(0-\infty)}$, Amount of unchanged API excreted in the urine at infinite time (7-10 half-lives); $\mathrm{T}_{1 / 2}$, Plasma concentration elimination half-life; \% fluctuation, $\left(C_{\max (s s)}-C_{\min (s s)}\right) / C_{\text {avg }} \cdot 100 ; \%$ swing, $\left(C_{\max (s)}-C_{\min (s s)}\right) / C_{\min } \cdot 100$.

Abbreviation: API, active pharmaceutical ingredient; $R \max$, maximum rate of excretion or release rate; Tlag, lag time.

pharmacodynamic endpoint is available. Pharmacodynamic evaluation is measurement of the effect on a pathophysiological process, such as a function of time, after administration of two different products to serve as a basis for BE assessment. Regulatory authorities request justification from the applicant for the use of pharmacodynamic effects/parameters for the establishment of BE criteria. These studies generally become necessary under two conditions 1 ) if the drug and/or metabolite(s) in plasma or urine cannot be analyzed quantitatively with sufficient accuracy and sensitivity; 2) if drug concentration measurement cannot be used as surrogate endpoints for the demonstration of efficacy and safety of the particular pharmaceutical product. The other important specifications for pharmacodynamic studies include i) a dose-response relationship should be demonstrated; ii) sufficient measurements should be taken to provide an appropriate pharmacodynamic response profile; iii) the complete dose-effect curve should remain below the maximum physiological response; iv) all pharmacodynamic measurements/methods should be validated for specificity, accuracy, and reproducibility. Examples of these pharmacodynamic studies include locally acting drug products and oral inhalation drug products, such as metered dose inhalers and dry powder inhalers, and topically applied dermatologic drug products, such as creams and ointments. Bronchodilator drug products, such as albuterol metered dose inhalers, produce relaxation of smooth muscle of the airways. For these drug products, a pharmacodynamic endpoint, based either on increase in forced expiratory volume in 1 second $\left(\mathrm{FEV}_{1}\right)$ or on measurement of PD20 or PC20 (the dose or concentration, respectively, of a challenge agent) is clinically relevant and may be used for BA and BE studies..$^{27,28}$

\section{Clinical endpoint studies or comparative clinical trials}

In the absence of pharmacokinetic and pharmacodynamic approaches, adequate and well-controlled clinical trials may be used to establish BA/BE. Several international regulatory authorities provide general information about the conduct of clinical studies to establish BE.

\section{In vitro endpoint studies}

More recently, a Biopharmaceutics Classification System (BCS) has categorized drug substances as having either high or low solubility and permeability and drug products as exhibiting rapid dissolution. ${ }^{29}$ According to this approach, drug substances may be classified into four primary groups: 1) highly soluble and highly permeable; 2) highly permeable and poorly soluble; 3 ) highly soluble and poorly permeable; 4) poorly soluble and poorly permeable. Using this BCS approach, a highly permeable, highly soluble drug substance formulated into a rapidly dissolving drug product may need only in vitro dissolution studies to establish BE. ${ }^{20}$ In addition, in vitro approaches to document $\mathrm{BE}$ for nonbioproblem drugs approved before 1962 remain acceptable as per FDA regulations. Dissolution tests can also be used to reduce the number of in vivo studies in other circumstances, and to i) assess batch-to-batch quality and support batch release; ii) provide process control and quality assurance; and iii) assess the need for further BE studies relative to minor post-approval changes, where they function as a signal of bioinequivalence..$^{20}$ The broad spectrum of BA/BE in vitro studies specifications were provided by each regulatory authority.

\section{General regulatory considerations for BA/BE studies}

The processes of study design and workflow of BA/BE studies are presented in brief in Figures 2 and 3, respectively. The general considerations for the advancement of conducting BA/BE studies are:

- Study design and protocol.

- Bioanalysis.

- Selection of appropriate analyte(s).

- BE metrics and data treatment.

- Statistical approaches and analysis. 


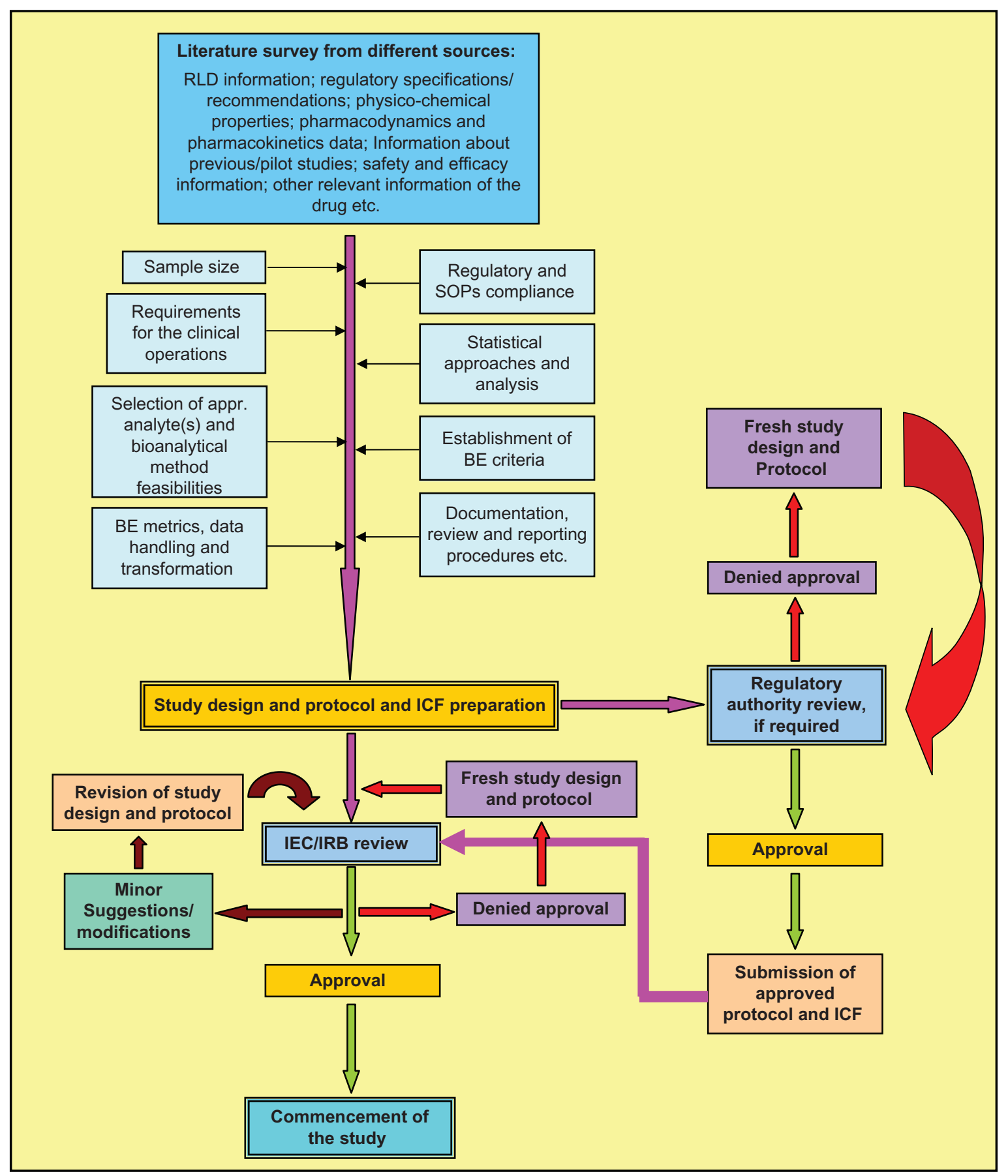

Figure 2 Brief process of bioequivalence study design and protocol approval.

Abbreviations: BE, bioequivalence; ICF, informed consent form; IEC, independent ethics committee; IRB, institutional review board; RLD, reference listed drug.

- Acceptance criteria for BE.

\section{Study design}

Successfully determining the BE of generic drugs to their respective reference drugs depends mostly on design and managing the conduct of study such that the highest quality samples are obtained. Some regulatory authorities (US: http:// www.accessdata.fda.gov/scripts/cder/drugsatfda/index.cfm;
Europe: http://www.medicines.org.uk/EMC/browsedocuments. aspx; Canada: http://webprod.hc-sc.gc.ca/dpd-bdpp/indexeng.jsp; Australia: https://www.ebs.tga.gov.au/) are providing specific information about Reference Listed Drug (RLD)/ reference product information on their websites, which makes it easy for investigators to proceed with $\mathrm{BA} / \mathrm{BE}$ study design. So, specific attention should be paid to selecting as well as collecting the appropriate reference product details. 


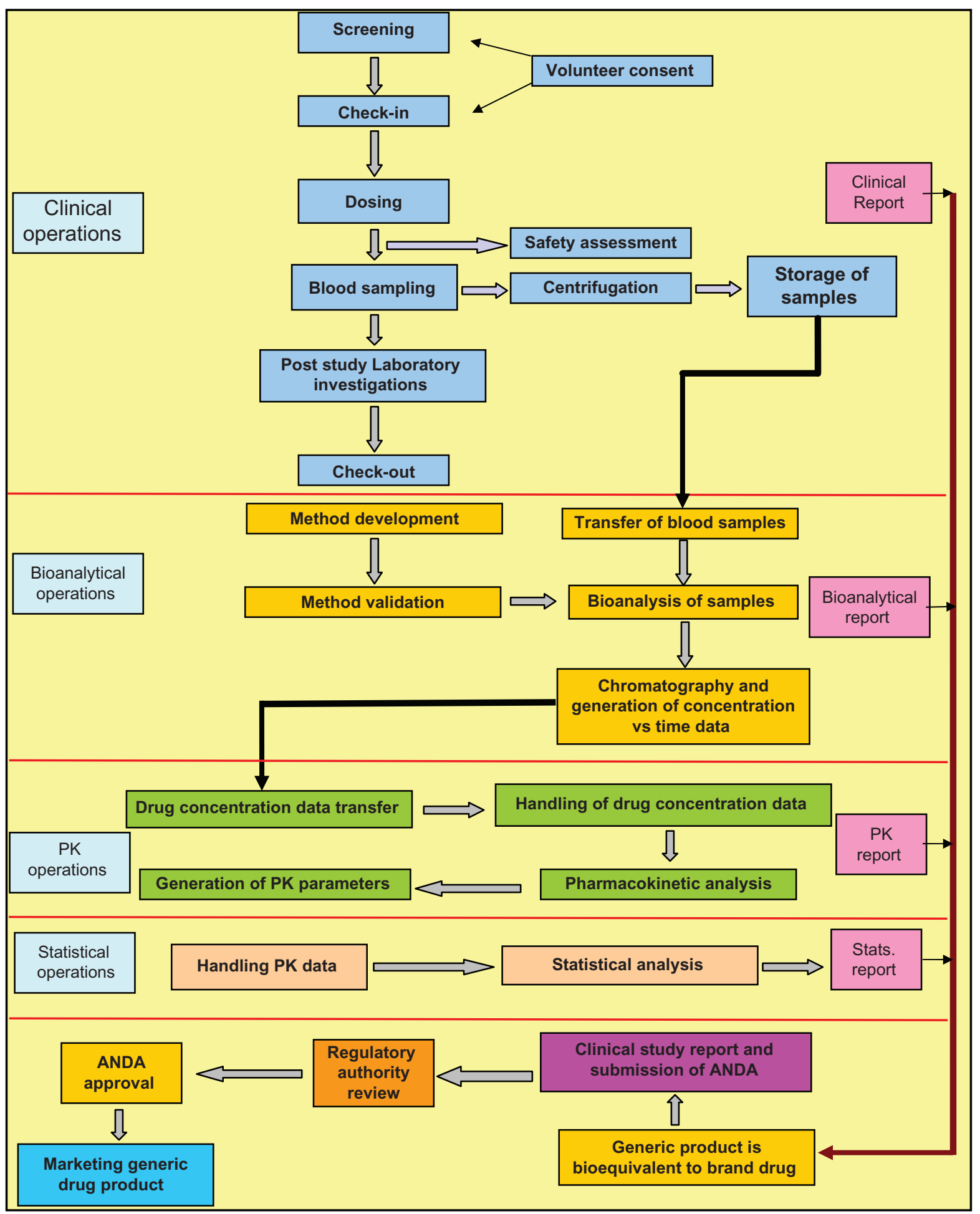

Figure 3 Brief representation of work flow of bioavailability/bioequivalence study. Abbreviations: ANDA, abbreviated new drug application; PK, pharmacokinetics.

The FDA provides Individual Product Bioequivalence Recommendations on their website (http://www.fda.gov/Drugs/ GuidanceComplianceRegulatoryInformation/Guidances/ ucm075214.htm), which substantially enhances understanding as well as planning to set the goals for establishing generic products. Attention should also be paid to: sizing the study properly (to achieve sufficient statistical power to demonstrate $\mathrm{BE})$; enrolling subjects as per relevant inclusion and exclusion criteria; ensuring that the appropriate overall design (simple two-period crossover, replicate design to gain direct information 
on within-subject variability for both test and reference product or parallel design) can adequately address the question at hand; standardization of the environmental conditions (such as, fasting, fed, ambulatory, supine); and ensuring that good clinical practices are strictly adhered to and documented. All of these should be planned a priori and embodied in the overall protocol and study plan for the smooth execution of BE studies.

Generally the study design and number of studies (singledose and/or multiple-dose and/or fasting and/or fed) depend on the RLD or reference product, physico-chemical properties of the drug, its pharmacokinetic properties, and proportionality in composition with justification along with respective regulatory guidance and specifications. Table 5 describes various study designs generally used for BA/BE studies.

Genetic variations among ethnic and/or racial background can alter the drug disposition (eg, white persons who predominantly express less P-glycoprotein in intestinal epithelial cells than black persons) and thus lead to potential sources of variability in pharmacokinetic parameters apart from geographical, food habits, and metabolic variations. For BE studies, these problems will be minimized using crossover designs, and hence US and Europe regulatory agencies (but not Japan, Korea, and Mexico, for example.) are accepting $\mathrm{BE}$ studies from other countries also, as these factors mostly do not have much effect on test and reference products. BE studies should be generally performed on a healthy population unless safety warranties (patient population should be preferred, if the risk associated with the drug is more in healthy population; eg, anticancer drugs) as they facilitate the provision of adequate information to detect formulation differences and allow extrapolation of this information to populations for which the brand drug is approved.

The regulatory specifications on strength to be investigated, demographics, sample size, number of studies required, fasting and/or fed requirements, standardization of experimental conditions (fluid intake, posture, and physical activity), add on design, and sampling and washout criteria are briefly described in Tables 6-13. As a result of random variation or a larger than expected relative difference, there is no guarantee that the sample size as calculated will pass the standards. If the study is run with the appropriate size and the standards are not met, the sponsor may add more subjects, and this approach is generally referred to as an "add-on" study (Table 12).

\section{Bioanalysis ${ }^{15-26,34-36}$}

In a general prospective of BA/BE studies, bioanalysis should be the subsequent step following clinical operations of the study (as shown in Figure 3), and it should be executed with strict adherence to good laboratory practices, standard operating procedures, and specific regulatory requirements. Bioanalysis is a term generally used to describe the quantitative measurement of a compound (drug) or its metabolite in biological fluids, primarily blood, plasma, serum, urine, or tissue extracts. ${ }^{34}$ Bioanalysis typically consists of two important components 1) sample preparation and 2) detection of the desired compound using a validated method. Excellent scientific and regulatory guidance documents are available that outline the requirements for a fully validated method. The application of validated methodology presupposes that the most appropriate analyte is monitored to attest to the question of BE.

\section{Selection of appropriate analyte(s)}

Each regulatory authority has its own specifications for selection of an appropriate analyte to be measured as well as consideration for BE. Most commonly, the investigator should consult the relevant regulatory agency for guidance on a particular therapeutic agent. The general considerations are discussed in the following sections.

\section{Parent drug vs metabolite(s)}

$\mathrm{BE}$ based on test/reference comparisons of pharmacokinetic measures serves two purposes 1) to act as a surrogate for therapeutic equivalence, 2) to provide in vivo evidence of pharmaceutical quality. The overall objective of $\mathrm{BE}$ is to ensure that generic products have efficacy and safety characteristics similar to those of the corresponding reference product. For the most part, traditional BE studies have been carried out on the basis of measurement of only the parent drug in body fluids such as plasma or serum. In some cases, however, monitoring a metabolite, or the parent and metabolite(s), may be more appropriate. A number of reasons for use of metabolite data have been put forward, ${ }^{35}$ such as i) the parent is an inactive prodrug, ii) plasma concentrations of the parent drug are too low to monitor because of inadequate assay sensitivity, iii) the parent drug is metabolized rapidly to an active metabolite, and iv) the parent drug and a metabolite both have therapeutic activities but the metabolite is present in higher concentrations when the parent drug is rapidly and extensively metabolized such that only metabolite(s) data are available. ${ }^{14}$

\section{Enantiomers vs racemates}

For BA/BE studies, measurement of both enantiomers may be important. For BE studies, measurement of the racemate using an achiral assay has been recommended, without measurement of individual enantiomers except when ${ }^{14}$ i) the enantiomers exhibit different pharmacodynamic characteristics; ii) the enantiomers exhibit different pharmacokinetics; iii) the 


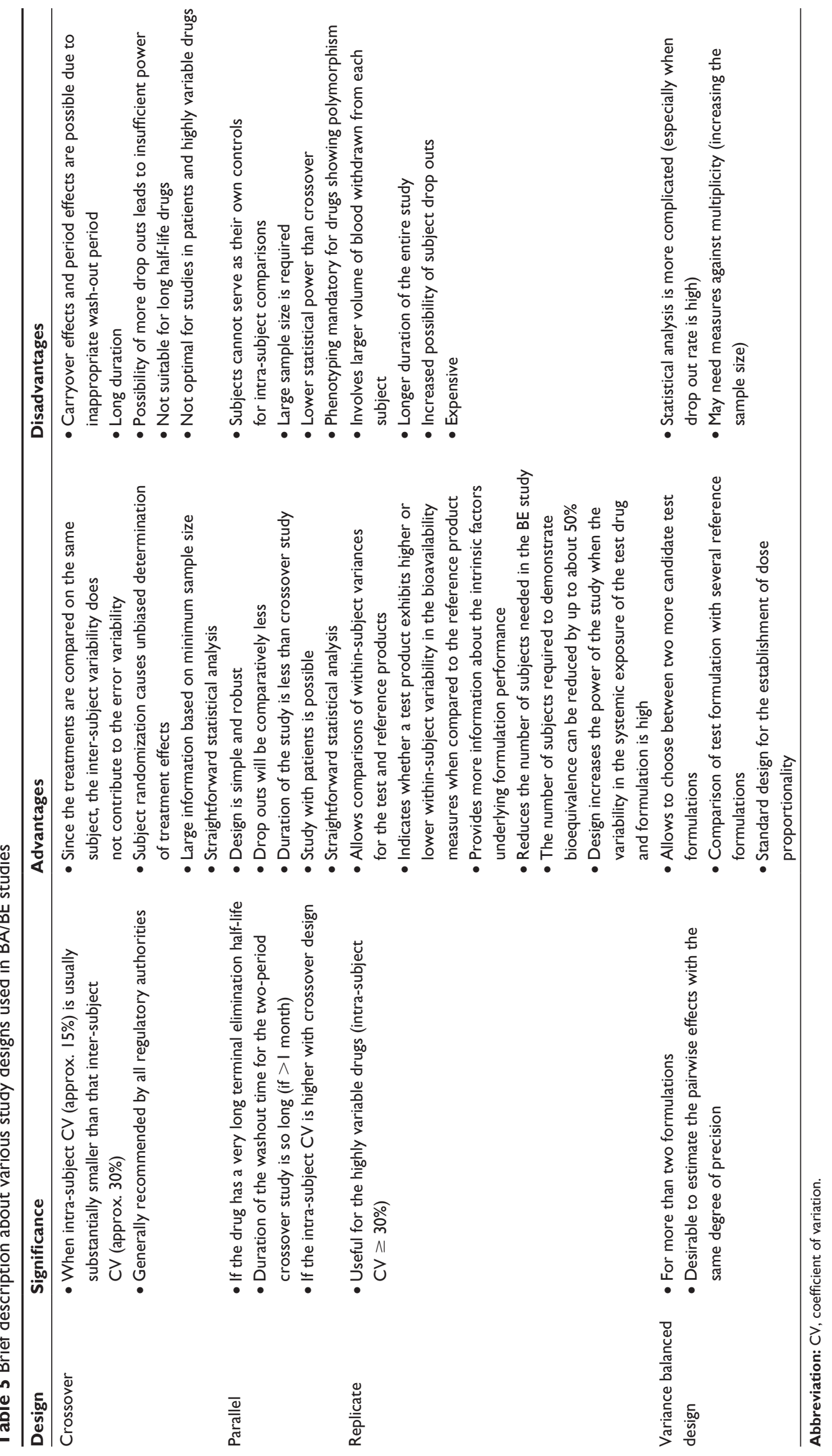




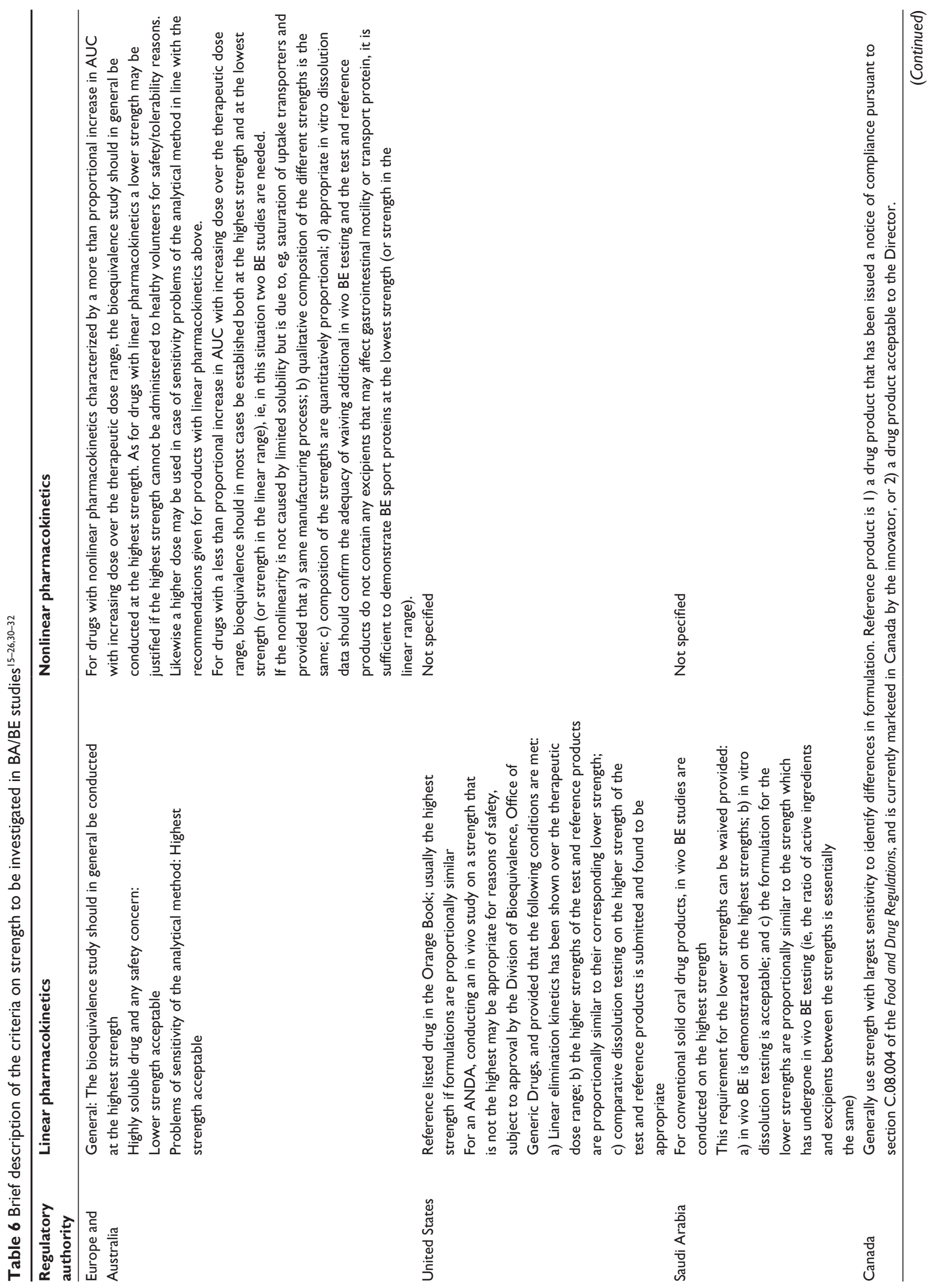


primary activity resides with the minor enantiomers; and iv) nonlinear absorption is present (as expressed by a change in the enantiomers concentration ratio with change in the input rate of the drug) for at least one of the enantiomers.

\section{Drug products with complex mixtures}

Certain drug products may contain complex drug substances, ie, active moiety or active ingredient(s), which are mixtures of multiple synthetic and/or natural source components. Some or all of the components of these complex drug substances may not be characterized by chemical structure and/or biological activity. In this circumstance, BA and BE studies may be based on selected markers of peak and total exposure. ${ }^{36}$

\section{$B E$ metrics and data treatment ${ }^{1,14,36}$}

The most frequent data treatment involves analysis of variance using a suitable program such as $\mathrm{SAS}^{\circledR}$ (Statistical Analysis System, SAS Institute, Cary, NC) or WinNonlin ${ }^{\circledR}$ (Pharsight Corporation, St. Louis, MO) so that contributions from subject, period, product/formulation, and interactions between these can be examined. Geometric mean ratios and $\log$ transformed data are examined to test the hypothesis that the $90 \%$ confidence interval of extent $\left(\mathrm{AUC}_{0-\mathrm{t}}\right.$ and $\left.\mathrm{AUC}_{0-\infty}\right)$ and the maximum concentration $\left(\mathrm{C}_{\max }\right)$ fall within the acceptance limits of $80 \%$ to $125 \%$. More recently, other data treatments have been popular, which include partial area measurements and exposure metrics including $\mathrm{C}_{\max }$ ' AUC, especially with highly variable drugs (HVDs), and with drugs having a long terminal $t_{1 / 2}$, specialized dosage forms, and/or whose time to $\mathrm{C}_{\text {max }}$ is considered important (eg, certain analgesics). In all of these cases, the objective has been to err on the side of protecting the consumer while at times increasing risk to the manufacturer. Hence, over the last 15 years, considerable debate has occurred globally about the fundamental scientific rationale used to establish BE for some of these "special" cases, in an effort to solve these issues associated with harmonization of drug equivalence approaches.

\section{Statistical approaches ${ }^{1,14-26,35-37}$}

Considerable debate has ensued over the past 20 years on statistical testing and BE studies. After protracted, wideranging, and in-depth discussion among various experts from different locations, specific statistical regulatory guidance is available to investigators conducting BE studies. The various pharmacokinetic parameters derived from the plasma concentration-time curve are subjected to ANOVA in which the variance is partitioned into components due to 
Table 7 Regulatory criteria on subject demographics for BA/BE studies ${ }^{15-26,30-32}$

\begin{tabular}{|c|c|c|c|}
\hline Regulatory authority & Sex & Age (years) & Body mass index (BMI) $\left(\mathrm{kg} / \mathrm{m}^{2}\right)$ \\
\hline India & Male or female & Healthy adult volunteers & Not specified \\
\hline Asia & Either sex & $18-55$ & 18-30; Asians: 18-25 \\
\hline United States & Both sexes & $\geq 18$ & Not specified \\
\hline Europe & Either sex & $\geq 18$ & $18.5-30$ \\
\hline Canada & Both sexes & $18-55$ & $\begin{array}{l}\text { Height/weight ratio for healthy volunteer subjects } \\
\text { should be within } 15 \% \text { of the normal range }\end{array}$ \\
\hline Australia & Either sex & $18-55$ & Accepted normal BMI \\
\hline South Africa & Either sex & $18-55$ & $\begin{array}{l}\text { Accepted normal BMI or Within } 15 \% \text { of the ideal } \\
\text { body mass or any other recognized reference }\end{array}$ \\
\hline Russia & Both sexes & $19-45$ & $\begin{array}{l}\text { Weight of body does not fall outside the } \\
\text { limits } \pm 15 \% \text { on Ketle total-height index }\end{array}$ \\
\hline Korea & Healthy adult & $19-55$ & Not specified \\
\hline Japan & Healthy adult & Not specified & Not specified \\
\hline People's Republic of China & Both sexes & $18-40$ & Standard weight range \\
\hline Mexico & $\begin{array}{l}\text { Avoiding pharmacokinetic } \\
\text { differences between sexes is } \\
\text { well documented; volunteers } \\
\text { of just one sex must be included }\end{array}$ & $18-55$ & Weight $10 \%$ from the ideal weight \\
\hline Saudi Arabia & $\begin{array}{l}\text { If females are included in the study, } \\
\text { the effects of gender differences } \\
\text { and menstrual cycle (if applicable) } \\
\text { are examined statistically. }\end{array}$ & $18-50$ & $\begin{array}{l}\text { Within } 15 \% \text { of ideal body weight, height, and } \\
\text { body build }\end{array}$ \\
\hline New Zealand & Both sexes & $\begin{array}{l}\text { Age range prior to the onset } \\
\text { of age-related physiological } \\
\text { changes (usually 18-60) }\end{array}$ & $\begin{array}{l}\text { Average weight (eg, within } \pm 15 \% \text { of their ideal } \\
\text { weight as given in the current Metropolitan Life } \\
\text { Insurance Company Height and Mass Tables) }\end{array}$ \\
\hline
\end{tabular}

subjects, periods, and treatments. The classical null hypothesis test is the hypothesis of equal means, H0: $\mu \mathrm{T}=\mu \mathrm{R}$ (ie, products are bioequivalent), where $\mu \mathrm{T}$ and $\mu \mathrm{R}$ represent the expected mean bioavailabilities of the test and reference products, respectively. The alternate hypothesis therefore is $\mathrm{H} 1: \mu \mathrm{T} \neq \mu \mathrm{R}$ (ie, products are bioinequivalent). ${ }^{35-37}$

The detection of the difference becomes simply a function of sample size, and since the probable magnitude of the difference is the critical factor, this gives rise to two anomalies: ${ }^{38}$ i) a large difference between two formulations which is nevertheless not statistically significant if error variability is high and/or sample size not large enough, ii) a small difference, probably of no therapeutic importance whatsoever, which is shown to be statistically significant if error variability is minimal and/or sample size adequately large.

The first case suggests a lack of sensitivity in the analysis, and the second an excess of it. Consequently, any practice that increases the variability of the study (sloppy design, assay variability, and within-formulation variability) would reduce the chances of finding a significant difference and hence improve the chances of concluding BE. The FDA therefore recognized that a finding of no statistical significance in the first case was not necessarily evidence of BE and consequently asked for a retrospective examination of the power of the test of null hypothesis. ${ }^{37}$

Adequate statistical approaches should be considered to establish the $\mathrm{BE}$ of generic product to that of reference product. Much worldwide discussion and interaction has focused on facilitating the appropriate statistical approaches to establish interchangeability between generic drug and reference drug. The pertinent statistical approaches include i) study power; ii) $75 / 75$ rule; and iii) $90 \%$ confidence interval. ${ }^{1}$

\section{Study power}

The conduct of a BE study should require some prior knowledge of the performance of the products (generic and brand drugs) in the human body so that an appropriate number of test subjects can be enrolled and provide adequate power to test the hypothesis with a reasonable likelihood (ie, at least $80 \%$ ) that the two products are indeed bioequivalent. In fact, the alternative hypothesis that two products (generic and brand drugs) are statistically different leads to the conclusion that they are not bioequivalent. The two criteria considered most important to understand are the inherent variability of the drug and the geometric mean ratio between the test and reference product. Both of these parameters can be determined through the conduct of a pilot study $(n=6-12)$ 
Table 8 Regulatory criteria on sample size for BA/BE studies ${ }^{15-26,30-32}$

\begin{tabular}{ll}
\hline Regulatory authority & Minimum \\
\hline India & $\begin{array}{l}\text { Should not be }<16 \text { unless justified } \\
\text { for ethical reasons }\end{array}$ \\
Asia & Should not be $<12$
\end{tabular}

Sample size specifications

The number of subjects required for a study should be statistically significant and should be sufficient to allow for possible withdrawals or removals (drop outs) from the study

The number of subjects required is determined by

a) The error variance associated with the primary characteristic to be studied as estimated from a pilot experiment, from previous studies or from published data; b) The significance level desired; c) The expected deviation from the reference product compatible with BE (delta, ie, percentage difference from 100\%); and d) the required power

United States

12

Europe

Canada

Should not be $<12$

12

$\begin{array}{ll}\text { Australia } & \text { Should not be }<16 \text { unless justified } \\ \text { South Africa } & \text { Should not be }<12 \text { (general); } \\ & 20 \text { subjects (for modified release } \\ & \text { oral dosage forms) }\end{array}$

Russia 18

Korea 12

Japan 20

Saudi Arabia A number of subjects of less than 24 may be accepted (with a minimum of 12 subjects) when statistically justifiable

New Zealand

12
A sufficient number of subjects should complete the study to achieve adequate power for a statistical assessment

The number of subjects to be included in the study should be based on an appropriate sample size calculation

a) Obtain an estimate of the intra-subject CV from the literature or from a pilot study; b) choose one of Figures 3.1 through 3.3 (mentioned in BE guidance document) by determining which one has the closest rounded-up CV to that estimated in a), above; c) choose an expected true ratio of test over reference means (usually 100\%) and move up the graph to the 0.90 probability of acceptance; $d$ ) a linear extrapolation between given sample sizes is adequate. This sample size calculation must be provided in the study protocol. More subjects than the sample size calculation required should be recruited into the study. This strategy allows for possible drop-outs and withdrawals

Same as that of Asian guidelines

The number of subjects should be justified on the basis of providing at least $80 \%$ power of meeting the acceptance criteria; Alternatively, the sample size can be calculated using appropriate power equations, which should be presented in the protocol

In quantity sufficient for ensuring statistical importance of study. Thus capacity of the statistical test for BE study must be supported at a level of not less than $80 \%$ for revealing $20 \%$ distinctions between comparison parameters

The number of subjects should meet the requirements for statistical validity. The number of subjects can be determined based on the characteristics of the active component of the pertinent drug products

A sufficient number of subjects for assessing $B E$ should be included. If $B E$ cannot be demonstrated because of an insufficient number, an add-on subject study can be performed using not less than half the number of subjects in the initial study. A sample size of 20 ( $n=10 /$ group) for the initial study and pooled size of 30 for initial plus addon subject study may suffice if test and reference products are equivalent in dissolution and similar in average $A \cup C$ and $C_{\max }$

Generally recommends a number of 24 normal healthy subjects. Should enroll a number of subjects sufficient to ensure adequate statistical results, which is based on the power function of the parametric statistical test procedure applied. The number of subjects should be determined using appropriate methods taking into account the error variance associated with the primary parameters to be studied (as estimated for a pilot experiment, from previous studies or from published data), the significance level desired $(\alpha=0.05)$, and the deviation from the reference product compatible with BE $( \pm 20 \%)$ and compatible with safety and efficacy

The number of subjects should provide the study with a sufficient statistical power (usually $\geq 80 \%$ ) to detect the allowed difference (usually $20 \%$ ) between the test and reference medicines for $A \cup C$ and $C_{\max }$. This number ( $n$ ) may, in many cases, be estimated in advance from published or pilot study data using formula

If the calculated number of subjects appears to be higher than is ethically justifiable, it may be necessary to accept a statistical power which is less than desirable. Normally it is not practical to use more than about 40 subjects in a bioavailability study

Mexico

Sample size must not be $<24$ subjects considering both sequences or it must meet the requirement related to a difference to be detected of $\pm 20 \%$ for the reference product's mean, associated with a type-l error $\left({ }^{*}\right)$ of 0.05 and a minimal potency of $(\mathrm{I}-*)$ of 0.8 for this kind of design. A sample size of $<24$ subjects must be scientifically justified

Brazil The number of healthy volunteers shall all times assure an adequate statistical power to guarantee reliability of BE study results 
to determine the proper sample size required for the pivotal study to establish BE as well as to minimize the possibility of undersizing the study. ${ }^{1}$

\section{5/75 rule}

This approach was the first application wherein individual BE (IBE) was being tested. The biomedical community felt that unless the change in the biological system was greater than $20 \%$ to $25 \%$, it would really not pose a significant clinical risk of invalidating the use of one therapeutic strategy versus another. This formed the basis for the 75/75 rule, which states that two products are equivalent if, and only if, at least $75 \%$ of the individuals being tested had ratios (of the various pharmacokinetic parameters obtained from the individual results) between the $75 \%$ and $125 \%$ limits, and the study conducted has the statistical power to detect a $20 \%$ difference between the two products. ${ }^{1}$ This approach was sound until the arrival of the $90 \%$ confidence interval. Later the $75 / 75$ rule lost most of its appeal when it was noted that both the test and reference products each have their own variability, and, therefore, a 90\% confidence interval approach was more appropriate for giving some consideration to the differential variability between the test and reference products. ${ }^{1}$

\section{$90 \%$ confidence interval}

Westlake $^{38}$ was the first to suggest the use of confidence intervals as a BE test to evaluate whether the mean amount of drug absorbed using the test formulation was close to the mean amount absorbed of the reference product. Subsequently, in July 1992, the guidance on Statistical Procedures for Bioequivalence Studies Using a Standard Two-treatment Crossover Design was released by the FDA. It was revised in 2001, and is available as Statistical Approaches to Establishing Bioequivalence (http://www.fda.gov/downloads/Drugs/ GuidanceComplianceRegulatoryInformation/Guidances/ ucm070244.pdf). This is based primarily on average BE $(\mathrm{ABE})$, wherein the average values for the pharmacokinetic parameters were determined for the test and reference products and compared using a $90 \%$ confidence interval for the ratio of the averages using a two one-sided $t$-tests procedure. ${ }^{39}$ The $\mathrm{ABE}$ approach for $\mathrm{BE}$, however, has limitations for addressing drug switchability, since it focuses only on the comparison of population averages between the test and reference formulations. This concept was really based on the fact that if the ratios of the two pharmacokinetic parameters of clinical interest (such as AUC, $\mathrm{C}_{\max }$ ) are to be compared, each with their own variability which may or may not be randomly distributed, then such a comparison can truly be done only through a confidence interval approach. This concept is well accepted by almost all regulatory authorities to establish the $\mathrm{BE}$.

The general statistical deliverables for a single-dose crossover BE study include summary statistics, ANOVA, 90\% confidence interval, ratio analysis, and intra-subject variability in addition to sequence, treatment, and period effects.

\section{Acceptance criteria for bioequivalence}

An equivalence approach is generally recommended, which usually relies on i) a criterion to allow the comparison; ii) a confidence interval for the criterion; and iii) a $\mathrm{BE}$ limit. Log transformation of exposure measures $\left(\mathrm{C}_{\max }\right.$ and $\left.\mathrm{AUC}\right)$ is generally recommended by various regulatory authorities. To compare measures in these studies, data are generally analyzed by using an average BE criterion with some considerations allowed for special category drugs. The general BE profile of generic vs brand product is shown in Figure 4.

\section{General}

To establish BE, the calculated $90 \%$ confidence interval should fall within a BE limit of $80 \%$ to $125 \%$ using logarithm transformed data (adopted since the concentration parameters $\mathrm{C}_{\max }$ and AUC may or may not be normally distributed). Currently, the BE limits of $80 \%$ to $125 \%$ have been applied to almost all drug products by regulatory authorities. More detailed information on acceptance criteria for $\mathrm{BE}$ is given in Table 14.

\section{For highly variable drugs}

In the context of BE, HVDs are considered to be drugs and drug products exhibiting intra-subject variability greater than $30 \%$ coefficient of variation in the pharmacokinetic measures, AUC and/or $\mathrm{C}_{\max }{ }^{39,40}$ Due to this high variability, large sample size may be needed in BE studies to give adequate statistical power to meet FDA BE limits, and thus designing BE studies for HVDs is challenging. Consequently development of generic products for HVDs is a major concern for the generic drugs industry. Major regulatory agencies also considered different approaches for evaluating BE of highly variable drugs. ${ }^{17-19,23,24,30}$ From 2004 onward the FDA started looking for alternative approaches to resolve this issue, and eventually found that replicate crossover design and scaled average BE provides a good approach for evaluating the BE of highly variable drugs and drug products as it would effectively decrease sample size, without increasing patient risk. ${ }^{41}$ Recently the FDA has issued Method for Statistical Analysis Using the Reference-Scaled Average Bioequivalence Approach for Progesterone Capsules, which 
Table 9 Regulatory criteria on number of studies required for conducting BA/BE studies ${ }^{15-26,30-33}$

\begin{tabular}{lll}
\hline Regulatory authority & Immediate-release formulations & Modified-release formulations \\
\hline India & Generally a single-dose, nonreplicate, fasting study & Should conduct fasting as well as food-effect studies \\
& $\begin{array}{l}\text { Food-effect studies are required I) when it is recommended } \\
\text { that the study drug should be taken with food (as would be } \\
\text { in routine clinical practice); } 2 \text { ) when fasting state studies }\end{array}$ & $\begin{array}{l}\text { If multiple-study design is important, appropriate } \\
\text { dosage administered and sampling carried out to } \\
\text { make assessment of } C_{\text {max }} \text { and } T_{\text {max }} \text { difficult }\end{array}$ \\
& document attainment of steady state
\end{tabular}

United States

Europe and Australia

Canada

South Africa

Korea

Japan

Saudi Arabia

New Zealand
If multiple-study design is important, appropriate dosage administered and sampling be carried out to document attainment of steady state

Generally two studies

- A single-dose, nonreplicate fasting study

- A food-effect, nonreplicate study

Food effect study can be excepted in the following cases:

I) When both test product and RLD are rapidly dissolving,

have similar dissolution profiles, and contain a drug substance with high solubility and high permeability (BCS Class I);

or 2) when the dosage and administration section of the RLD label states that the product should be taken only on an empty stomach; or 3) when the RLD label does not make any statements about the effect of food on absorption or administration If food effect mentioned in RLD label and if multiple-study design is important, appropriate dosage administered and sampling be carried out to document attainment of steady state

Generally a single-dose, nonreplicate, fasting study Food-effect studies are required if the Summary of Product Characteristics of the reference product contains specific recommendations in relation with food interaction.

Generally comparative BA studies conducted in the fasting state.

Fed study is acceptable if there is a documented serious safety risk to subjects from single-dose administration of the drug or drug product in the absence of food, then an appropriately designed study conducted in the presence of only a sufficient quantity of food to prevent the toxicity may be acceptable for purposes of $B E$ assessment For complicated IR formulations (narrow therapeutic range drugs, highly toxic drugs and nonlinear drugs): Both fasted and fed studies

Should be done under fasting conditions unless food effects affect bioavailability of drug or reference product dosage recommended

Generally a single-dose, nonreplicate, fasting study

Both fasting as well as food-effect studies

Generally a single dose, nonreplicate, fasting study is required. Food-effect studies are required I) If documented evidence of effect of food on drug absorption 2) The drug is recommended to be administered with food 3) The drug may produce gastric irritation under fasting conditions, thus may be taken with food

Generally a single dose fasting study is required.

Fed study is required when it is recommended that the drug be given with food or fasted studies make assessment of $\mathrm{C}_{\text {max }}$ and $\mathrm{T}_{\text {max }}$ difficult
Should conduct fasting as well as food-effect studies If multiple-study design is important, appropriate dosage administered and sampling be carried out to document attainment of steady state

Should conduct fasting, food-effect as well as steady-state studies

Usual requirement is for both fasted and fed studies If multiple-study design is important, appropriate dosage administered and sampling be carried out to document attainment of steady state

Both fed and fasted studies are required If multiple-study design is important, it should be carried out as per regulatory specifications Should conduct fasting, food-effect as well as steady-state studies

Should conduct fasting, food-effect as well as steady-state studies

Should conduct fasting as well as food-effect studies

Should conduct fasting as well as food-effect studies Steady state studies are generally required if the drugs are likely to accumulate along with singledose studies.

Abbreviations: BCS, Biopharmaceutics Classification System; IR, immediate release; RLD, reference listed drug. 
Table I 0 Regulatory criteria for conducting fasting and fed BA/BE studies ${ }^{15-26,30-33}$

\begin{tabular}{ll}
\hline Regulatory authority & Fasting requirements \\
\hline India & $\begin{array}{l}\text { Overnight fast (at least } 10 \mathrm{~h} \text { ), with a } \\
\text { subsequent fast of } 4 \mathrm{~h} \text { following dosing } \\
\text { For multiple-dose fasting studies, when } \\
\text { an evening dose must be given, } 2 \mathrm{~h} \text { before } \\
\text { and after the dosing }\end{array}$ \\
United States & Following an overnight fast of at least $10 \mathrm{~h}$,
\end{tabular}

United States with a subsequent fast of $4 \mathrm{~h}$ post dose

Europe and Australia

Canada

South Africa

Korea

Saudi Arabia

New Zealand
Should fast for at least $8 \mathrm{~h}$ prior to dosing, unless otherwise justified and no food is allowed for at least $4 \mathrm{~h}$ post dose
Fed study requirement

950-1000 kcal of high-fat breakfast approximately $15 \mathrm{~min}$ before dosing (at least $50 \%$ of calories must come from fat, $15 \%-20 \%$ from proteins and rest from carbohydrates)

The vast ethnic and cultural restrictions of the Indian subcontinent preclude the recommendation by a single standard high fat; in this case protocol should specify the appropriate and suitable diet

A high-fat (approximately $50 \%$ of total caloric content of the meal), highcalorie (approximately 800-1000 calories) meal is recommended. This test meal should derive approximately 150, 250, and 500-600 calories from protein, carbohydrate, and fat, respectively. The caloric breakdown of the test meal should be provided in the study report. If the caloric breakdown of the meal is significantly different from the one described above, should require a scientific rationale for this difference Following an overnight fast of at least $10 \mathrm{~h}$, subjects should start the recommended meal 30 min prior to dosing. Study subjects should eat this meal in 30 min or less; however, the drug product should be administered 30 min after start of the meal

The composition of the meal is recommended to be according to the SPC of the originator product. If no specific recommendation is given in the originator SPC, the meal should be a high-fat (approximately $50 \% \mathrm{t}$ of total caloric content of the meal) and high-calorie (approximately 800 to $1000 \mathrm{kcal})$ meal. This test meal should derive approximately 150 , 250 , and 500-600 kcal from protein, carbohydrate, and fat, respectively. The composition of the meal should be described in terms of protein, carbohydrate, and fat content (specified in grams, calories, and relative caloric content (\%))

Should be a representative meal in which sufficient food is given to allow potential perturbation of systemic BA of the drug from the drug product. The sponsor should justify the choice of meal and relate the specific components and timing of food administration

Example: 2 eggs fried in butter, 2 strips of bacon, 2 slices of toast with butter, I $20 \mathrm{~g}$ of hash browns and $240 \mathrm{~mL}$ of whole milk Use of high-calorie and high-fat meals is recommended

High-fat diet should be taken within 20 min in at least a 10 -h fasting state. The drug products should be administered $30 \mathrm{~min}$ after the meal starts

A high-fat (approximately $50 \%$ of total caloric content of the meal), high-calorie (approximately 1000 calories) breakfast. Alternative meals with equivalent nutritional content can be used

The meal should contain approximately $30-40 \mathrm{~g}$ of fat a subsequent fast of $2-4 \mathrm{~h}$ following dose administration

Abbreviation: SPC, summary of product characteristics.

clearly states how to perform statistical analysis for HVDs, such as progesterone using the replicate crossover design and reference-scaled ABE approach (more information is available at: http://www.fda.gov/downloads/Drugs/ GuidanceCompliance RegulatoryInformation/Guidances/ UCM209294.pdf). The various regulatory agency acceptance criteria for HVDs are given in Table 15.

\section{For narrow therapeutic index drugs (NTIDs)}

NTIDs can be defined as drugs that require therapeutic drug concentration or pharmacodynamic monitoring and/or drugs for which drug product labeling indicates a narrow therapeutic range designation. Perhaps tighter restrictions on these drugs would aid in the establishment of truly bioequivalent drug products within this class. Thus, additional testing and controls may be needed to ensure the quality of these drug products. An NTIDs list was prepared by the Center for Drug Evaluation and Research and available in the Scale-Up and Post-Approval Changes for Intermediate Release Products (more information is available at http://www.fda.gov/downloads/Drugs/ GuidanceComplianceRegulatoryInformation/Guidances/ 


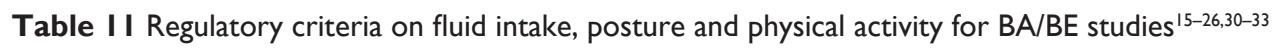

\begin{tabular}{llc}
\hline Regulatory authority & Fluid intake & Posture and physical activity \\
\hline India & Standardization of fluid intake and physical activity is required and it should be stated in protocol \\
United States & Subjects should be administered the drug product & Standardized
\end{tabular}

Asia, Europe, and Australia

Canada

South Africa

Korea

Saudi Arabia

New Zealand with $240 \mathrm{~mL}$ (8 fluid ounces) of water; water is not allowed as desired except for I $\mathrm{h}$ before and $\mathrm{I} \mathrm{h}$ after the drug administration

The drug products should be administered with a standardized volume of fluid (at least $150 \mathrm{~mL}$ ) Prior to and during each study phase, subjects should be allowed water as desired except for one hour before and after drug administration

On the morning of the study, up to $250 \mathrm{~mL}$ of water may be permitted up to $2 \mathrm{~h}$ before drug administration. The dose should be taken with water of a standard volume $(\mathrm{eg}, 150 \mathrm{~mL})$ and at a standard temperature. Two hours after drug administration, $250 \mathrm{~mL}$ of xanthine-free fluids is permitted

The volume of fluid administered at the time of dosing should be constant (eg, $200 \mathrm{~mL}$ ); fluids taken after dosing should also be standardized

Drug products should be administered with $240 \mathrm{~mL}$ of water; drinking water I $\mathrm{h}$ before and after the administration of drug products is not allowed

The test or reference products should be administered with about 8 fluid ounces $(240 \mathrm{~mL})$ of water; water allowed as desired except for I h before and after drug administration

The quantity, type, and timing of food and fluid taken concurrently with the medicine should be stated, and should be controlled
As the bioavailability of an active moiety from a dosage form could be dependent upon gastrointestinal transit times, and regional blood flows, posture and physical activity may need to be standardized

For most drugs, subjects should not be allowed to recline until at least $2 \mathrm{~h}$ after drug ingestion. Physical activity and posture should be standardized as much as possible to limit effects on gastrointestinal blood flow and motility. The same pattern of posture and activity should be maintained for each study day

Should be standardized

Subjects should not be in a supine position at least $2 \mathrm{~h}$ after the administration of drug products, and should maintain a posture and do only activities that would minimize the effects on their gastrointestinal blood flow rate and motility Appropriate restrictions on fluid intake and physical activities should be made

Standardization of posture and physical activity is important. Subjects should not be allowed to recline until at least $2 \mathrm{~h}$ after oral administration of the medicine.

Table I 2 Regulatory "add-on criteria” for conducting BA/BE studies $16-18,21,23,30$

\begin{tabular}{|c|c|}
\hline Regulatory authority & Add-on criteria \\
\hline Europe and Australia & $\begin{array}{l}\text { It is acceptable to use a two-stage approach when attempting to demonstrate BE. An initial group of subjects can be } \\
\text { treated and their data analysed. If BE has not been demonstrated an additional group can be recruited and the results } \\
\text { from both groups combined in a final analysis. If this approach is adopted appropriate steps must be taken to preserve the } \\
\text { overall type I error of the experiment and the stopping criteria should be clearly defined prior to the study. The analysis of } \\
\text { the first stage data should be treated as an interim analysis and both analyses conducted at adjusted significance levels }\end{array}$ \\
\hline South Africa & $\begin{array}{l}\text { If the BE study was performed with the appropriate size but BE cannot be demonstrated because of a result of a larger than } \\
\text { expected random variation or a relative difference, an add-on subject study can be performed using not less than half the } \\
\text { number of subjects in the initial study. Combining is acceptable only if the same protocol was used and preparations from } \\
\text { the same batches were used. Add-on designs must be carried out strictly according to the study protocol and standard } \\
\text { operating procedures, and must be given appropriate statistical treatment, including consideration of consumer risk }\end{array}$ \\
\hline Canada & $\begin{array}{l}\text { As a result of random variation or a larger than expected relative difference, there is no guarantee that the sample size as } \\
\text { calculated will pass the standards. If the study is run with the appropriate size and the standards are not met, the sponsor } \\
\text { may add more subjects (a minimum of I2). The same protocol should be used (ie, same formulations, same lots, same blood } \\
\text { sampling times, a minimum number of I } 2 \text { subjects). The choice to use this strategy, as with all designs, should be declared } \\
\text { and justified a priori.The level of confidence should be adjusted using the Bonferroni procedure. The } t \text {-value should be that } \\
\text { for } P=0.025 \text { instead of } 0.05\end{array}$ \\
\hline Japan & Also for add-on study an additional 10 subjects is recommended along with initial subjects \\
\hline
\end{tabular}


Table 13 Regulatory criteria on sampling and washout period for conducting BA/BE studies ${ }^{15-26,30-32}$

\begin{tabular}{|c|c|c|}
\hline Regulatory authority & Sampling criteria & Washout criteria \\
\hline India & $\begin{array}{l}\text { Blood sampling } \\
\text { Should be extended to at least } 3 \text { elimination half lives; at least } 3 \text { sampling points } \\
\text { during absorption phase, } 3-4 \text { at the projected } T_{\text {max }} \text {, and } 4 \text { points during elimination phase; } \\
\text { sampling should be continued for a sufficient period to ensure that } A U C_{0-t} \text { to } A \cup C_{0-\infty} \text { is } \\
\text { only a small percentage (normally }<20 \% \text { ) of the total AUC. Truncated AUC is } \\
\text { undesirable except in the presence of enterohepatic recycling } \\
\text { Urinary sampling } \\
\text { Collect urine samples for } 7 \text { or more half-lives }\end{array}$ & $\begin{array}{l}\text { Adequate and ideally } \\
\text { it should be } \geq 5 \\
\text { half-lives of the moieties } \\
\text { to be measured }\end{array}$ \\
\hline United States & $\begin{array}{l}\text { Blood samples should be drawn at appropriate times to describe the absorption, } \\
\text { distribution, and elimination phases of the drug; } 12-18 \text { samples, including a } \\
\text { predose sample, should be collected per subject per dose; should continue } \\
\text { for at least } 3 \text { or more terminal half-lives of the drug }\end{array}$ & $\begin{array}{l}\text { An adequate washout } \\
\text { period (eg, more than } \\
5 \text { half-lives of the moieties } \\
\text { to be measured) }\end{array}$ \\
\hline Europe & $\begin{array}{l}\text { Single-dose blood sampling } \\
\text { Sufficient sampling is required; frequent sampling around predicted } \mathrm{T}_{\max } ; \text { avoid } \mathrm{C}_{\max } \text { be } \\
\left.\text { the first point; accommodate reliable estimate }\left(A \cup \mathrm{C}_{0-\tau}\right) \text { covers at least } 80 \% \text { of } A \cup C_{0-\infty}\right) \text {; }\end{array}$ & $\begin{array}{l}\text { Sufficient washout } \\
\text { period (usually at least } \\
5 \text { terminal half-lives) }\end{array}$ \\
\hline
\end{tabular}

at least 3-4 points during the terminal log-linear phase; AUC truncated at $72 \mathrm{~h}\left(\mathrm{AUC}_{0-72 \mathrm{~h}}\right)$ may be used as an alternative to $\mathrm{AUC}_{0-\mathrm{t}}$ or comparison of extent of exposure

\section{Multiple-dose blood sampling}

Pre-dose sample should be taken immediately before (within $5 \mathrm{~min}$ ) dosing and

the last sample is recommended to be taken within $10 \mathrm{~min}$ of the nominal time

for the dosage interval to ensure an accurate determination of $A \cup C_{0-\tau}$

Urinary sampling

Urine should normally be collected over no less than 3 times the terminal

elimination half-life

Australia Single-dose blood sampling

Should provide adequate estimation of $\mathrm{C}_{\text {max }}$; cover plasma concentration time curve long enough to provide a reliable estimation of the extent of absorption; 3-4 samples during the terminal log-linear phase. AUC truncated at $72 \mathrm{~h}$ is permitted for long half-life drugs

\section{Multiple-dose blood sampling}

When differences between morning and evening or nightly dosing are known,

sampling should be carried out over a full 24-h cycle

Canada Blood sampling

Sampling should be sufficient to account for at least $80 \%$ of the known $A \cup C_{0-\infty}, C_{\max }$ and terminal disposition; 3 times the terminal half-life of the drug; 12-18 samples should be collected per each subject per dose; 4 or more points be determined during the terminal log-linear phase

Urine sampling

Urine should be collected over no less than 3 times the terminal elimination

half-life. For a 24-h study, sampling times of $0-2,2-4,4-8,8-12$, and I2-24 h

are usually appropriate.

South Africa

\section{Blood sampling}

Sampling should be sufficient to account for at least $80 \%$ of the known $A \cup C_{0-\infty}, C_{\text {max }}$; collecting at least 3-4 samples above the LOQ during the terminal log-linear phase; sampling period is approximately thee terminal half-lives of the drug; AUC truncated at $72 \mathrm{~h}$ is permitted for long half-life drugs; 12-18 samples should be collected per each subject per dose; at least 3-4 samples above LOQ should be obtained during the terminal log-linear phase

Urine sampling

Sufficient urine should be collected over an extended period and generally no less than 7 times the terminal elimination half-life; for a $24-h$ study,

sampling times of $0-2,2-4,4-8,8-12$, and $12-24$ h post dose are usually appropriate

Blood sampling

Sampling should be sufficient to estimate all the required parameters for BA; cover

3 or more times the terminal half-life; at least 2 points before $T_{\text {max }}$; sufficient to account

for at least $80 \%$ of the known $A \cup C_{0-\infty}$; number of blood samples should be $>12$;

AUC truncated at $72 \mathrm{~h}$ is permitted for long half-life drugs

Urine sampling

Adequate number of urine samples should be covered to estimate the amount and excretory rate
Adequate washout period

Normally should be not less than 10 times the mean terminal half-life of the drug. Normally, the interval between study days should not exceed 3-4 weeks

Adequate washout period

Adequate and should be $>5$ times the half-life of the active ingredients

(Continued) 
Table 13 (Continued)

\begin{tabular}{|c|c|c|}
\hline Regulatory authority & Sampling criteria & Washout criteria \\
\hline Saudi Arabia & $\begin{array}{l}\text { Sufficient samples are collected to estimate all the required parameters during } \\
\text { absorption and elimination for BE assessment. A sampling period extending to } \\
\text { at least 4-5 terminal elimination half-lives of the drug or 4-5 the longest half-live } \\
\text { of the pertinent analyte (if more than I analyte) is usually sufficient }\end{array}$ & $\begin{array}{l}\text { An adequate washout } \\
\text { period (eg, more than } 5 \\
\text { half-lives of the moieties } \\
\text { to be measured) }\end{array}$ \\
\hline New Zealand & $\begin{array}{l}\text { Single-dose blood sampling } \\
\text { Sampling should be sufficient to account for at least } 80 \% \text { of the known AUC }{ }_{0-\infty} \text {; should } \\
\text { extend to at least } 3 \text { elimination half-lives of the drug; truncated AUC is undesirable } \\
\text { except in unavoidable circumstances like the presence of enterohepatic recycling } \\
\text { Multiple dose-blood sampling } \\
\text { Sampling should be carried out over a full } 24 \text {-h cycle so that any effects of circadian } \\
\text { rhythms may be detected, unless these rhythms can be argued not to have } \\
\text { practical significance } \\
\text { Urine sampling } \\
\text { Adequate number of urine samples should be covered to estimate the amount } \\
\text { and excretory rate. For a } 24-h \text { study, sampling times of } 0-2,2-4,4-8,8-12 \text {, } \\
\text { and } 12-24 \text { h are usually appropriate. Where urinary excretion is measured in a } \\
\text { single-dose study it is necessary to collect urine for } 7 \text { or more half-lives }\end{array}$ & $\begin{array}{l}\text { An adequate washout } \\
\text { period (at least } 3 \text { times } \\
\text { the dominating half-life) }\end{array}$ \\
\hline
\end{tabular}

Abbreviation: LOQ, limit of quantification.

ucm070636.pdf). The regulatory acceptance criterion for NTIDs is given in Table 15.

\section{Future prospects}

The adaptation of the BA/BE concept worldwide for over 20 years has enabled the production and approval of quality generic products through profound scientific, technical, and regulatory advances (especially through replicate designs, application of BCS, scaled average BE) by various approaches to assess BE for various complex and special groups of drugs. This continuing success story of $\mathrm{BA} / \mathrm{BE}$ is based on the contribution to efficacy, safety, and quality by international regulatory authorities, pharma industry researchers, academic researchers, and indeed the efforts from $\mathrm{ICH}, \mathrm{WHO}$, and various international conferences. However, a lot remains to be done, especially to promote global harmonization of BA/BE approaches, which should focus on uniformity, standardization of nomenclature, agreement on general concepts, alternative approaches for locally acting drug products, choice of test procedures, outlier

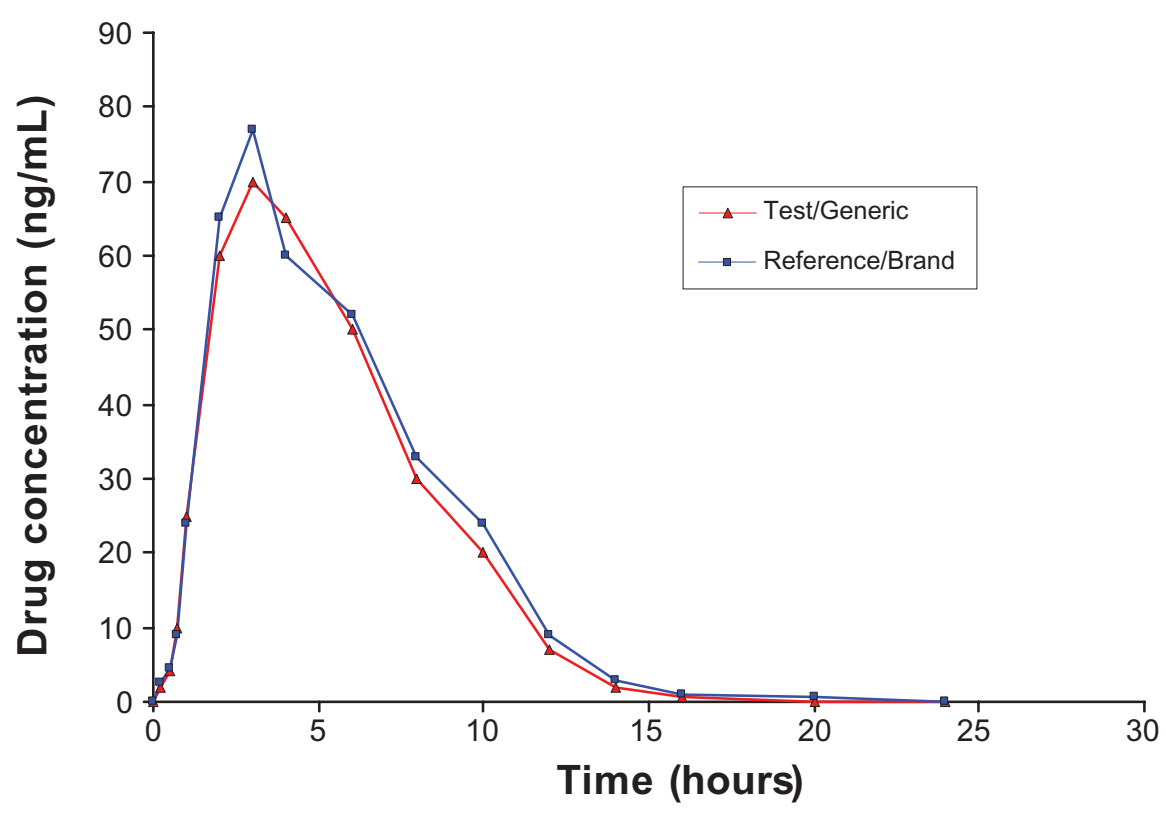

Figure 4 General bioequivalence profile of generic vs brand products. 
Table I4 Regulatory acceptance criteria for bioequivalence ${ }^{15-26,30-32}$

\begin{tabular}{|c|c|c|c|c|c|c|}
\hline \multirow[t]{3}{*}{ Regulatory authority } & \multicolumn{6}{|c|}{$\mathbf{9 0} \%$ confidence interval on Log transformed data } \\
\hline & \multicolumn{3}{|l|}{ Single-dose study } & \multicolumn{3}{|c|}{ Steady-state study } \\
\hline & $\mathbf{C}_{\max }$ & AUC $_{0-\mathrm{t}}$ & $\mathrm{AUC}_{0-\infty}$ & $\mathbf{C}_{\max }$ & $\mathbf{C}_{\min }$ & AUC $_{\tau}$ \\
\hline India & $80-125$ & $80-125$ & $80-125$ & $80-125$ & $80-125$ & $80-125$ \\
\hline Asia & $80-125$ & $80-125$ & $80-125$ & $80-125$ & $80-125$ & $80-125$ \\
\hline United States & $80-125$ & $80-125$ & $80-125$ & $80-125$ & $80-125$ & $80-125$ \\
\hline Europe & $80-125$ & $80-125$ & Not applicable & $80-125$ & Not applicable & $80-125$ \\
\hline Canada & $\begin{array}{l}\text { Ratio must be } 80-125 \text {. Need to pass } \\
\text { also on potency corrected data } \\
\text { Add-on studies may be allowed if } \\
\text { intra-CV greater than expected }\end{array}$ & $80-125$ & Not applicable & $80-125$ & $80-125$ & $80-125$ \\
\hline Australia & $80-125$ & $80-125$ & Not applicable & $80-125$ & $80-125$ & $80-125$ \\
\hline South Africa & $75-133$ & $80-125$ & Not applicable & $75-133$ & $75-133$ & $\begin{array}{l}80-125 \\
\text { (including \% swing } \\
\text { and \% fluctuation) }\end{array}$ \\
\hline Russia & $75-133$ & $80-125$ & $80-125$ & $75-133$ & $75-133$ & $80-125$ \\
\hline Korea & $80-125$ & $80-125$ & $80-125$ & $80-125$ & $80-125$ & $80-125$ \\
\hline Mexico & $80-125$ & $80-125$ & Not applicable & $80-125$ & $80-125$ & $80-125$ \\
\hline Saudi Arabia & $80-125$ & $80-125$ & $80-125$ & $80-125$ & $80-125$ & $\begin{array}{l}80-125 \\
\text { (including \% swing } \\
\text { and \% fluctuation) }\end{array}$ \\
\hline New Zealand & $80-125$ & $80-125$ & $80-125$ & $80-125$ & $80-125$ & $80-125$ \\
\hline
\end{tabular}

Abbreviation: $\mathrm{CV}$, coefficient of variation.

challenge, consideration of BE criteria and objectives, all of which reflect regulatory decision-making standards, as well as ensuring product quality over time for both innovator and generic drugs. To achieve these objectives efforts should continue from international health organizations, pharmaceutical industries, researchers, and regulatory authorities to understand and to develop more efficient and scientifically valid approaches to assess BE, and develop generic drugs in a cost-effective manner.

\section{Acknowledgments}

The authors are grateful to Cytel Management, Pune for the kind help and support during the literature survey and preparation of the manuscript. The authors are also thankful

Table I5 Regulatory BA/BE acceptance criteria for special class drugs ${ }^{17-20,23,24,30}$

\begin{tabular}{|c|c|c|c|c|}
\hline \multirow[t]{2}{*}{$\begin{array}{l}\text { Regulatory } \\
\text { authority }\end{array}$} & \multicolumn{2}{|c|}{$\begin{array}{l}\text { Highly variable drugs } 90 \% \text { confidence interval Log transformed } \\
\text { data }\end{array}$} & \multicolumn{2}{|c|}{$\begin{array}{l}\text { Narrow therapeutic index drugs } 90 \% \\
\text { confidence interval Log transformed data }\end{array}$} \\
\hline & $\mathbf{C}_{\max }$ & AUC & $\mathbf{C}_{\max }$ & $\mathrm{AUC}_{0-\mathrm{t}}$ \\
\hline Asia & $\begin{array}{l}\text { The interval must be prospectively } \\
\text { defined, eg, } 0.75-1.33 \text { and justified } \\
\text { for addressing in particular any safety } \\
\text { or efficacy concerns for patients } \\
\text { switched between formulations }\end{array}$ & $\begin{array}{l}\text { In rare cases a wider acceptance } \\
\text { range may be acceptable } \\
\text { if it is based on sound clinical } \\
\text { justification }\end{array}$ & $\begin{array}{l}\text { Acceptance interval } \\
\text { may need to be } \\
\text { tightened }\end{array}$ & $\begin{array}{l}\text { Acceptance interval } \\
\text { may need to be tightened }\end{array}$ \\
\hline United States & $\begin{array}{l}\text { GMR }(80-125) 95 \% \text { upper bound } \\
\text { for }(\mu T-\mu R) / \delta 2 \text { WR } \leq 0.7976 \\
\text { (using scaled average approach) }\end{array}$ & $\begin{array}{l}\text { GMR }(80-125) 95 \% \text { upper bound } \\
\text { or }(\mu T-\mu R) / \delta 2 \text { WR } \leq 0.7976 \\
\text { (using scaled average approach) }\end{array}$ & $80-125$ & $80-125$ \\
\hline Europe* & - & - & $90.00-111.11$ & $90.00-111.11$ \\
\hline Canada & GMR (80-125) & GMR (80-125) 90\% Cl (80-125) & - & - \\
\hline Saudi Arabia & $75-133$ & $\begin{array}{l}\text { Wider acceptance range may } \\
\text { be acceptable and this should } \\
\text { be justified clinically }\end{array}$ & $90-111$ & - \\
\hline Japan & - & - & $90.00-111.11$ & $90.00-111.11$ \\
\hline
\end{tabular}

Notes: *For highly variable drugs: a wider difference in $C_{\text {max }}$ is considered relevant based on a sound clinical justification. If this is the case the acceptance criteria for $C_{\text {mat }}$ can be widened to a maximum of $69.84 \%-143.19 \%$. For this acceptance BE study must be a replicate design where it has been demonstrated that intra-subject $\mathrm{CV}$ for $\mathrm{C}_{\max }$ of reference drug is $>30 \%$. The applicant should justify the calculated intra-subject $\mathrm{CV}$ is a reliable estimate and that it is not the result of outliers and the request for widened interval must be prospectively specified in the protocol.

Abbreviations: $\mathrm{CV}$, coefficient of variation; GMR, geometic mean ratio. 
to Mr Deepak Bansal, Infosys Technologies Ltd., India for his enormous inspiration to prepare this manuscript.

\section{Disclosure}

The authors report no conflicts of interest in this work.

\section{References}

1. Midha1 KK, McKay G. Bioequivalence: its history, practice, and future. AAPS J. 2009;11:664-670.

2. Haas JS, Phillips KA, Gerstenberger EP, Seger AC. Potential savings from substituting generic drugs for brand-name drugs: medical expenditure panel survey, 1997-2000. Ann Intern Med. 2005;142:891-897.

3. Shrank WH, Cox ER, Fisher MA, Mehta J, Choudhry NK. Patients' perceptions of generic medications. Health Aff. 2009;28:546-556.

4. US Food and Drug Administration. Orange Book: Approved Drug Products with Therapeutic Equivalence Evaluations. http:// www.accessdata.fda.gov/scripts/cder/ob/default.cfm. Accessed November 25, 2010.

5. US Food and Drug Administration, Drugs@FDA Glossary of Terms. http://www.fda.gov/Drugs/InformationOnDrugs/ucm079436.htm\#G. Accessed November 25, 2010.

6. Guidance for Industry Bioavailability and Bioequivalence Studies for Orally Administered Drug Products - General Considerations. US Department of Health and Human Services, Food and Drug Administration Center for Drug Evaluation and Research (CDER), March 2003. http://www.fda.gov/downloads/Drugs/GuidanceComp lianceRegulatoryInformation/Guidances/ucm070124.pdf. Accessed November 25, 2010.

7. European Medicines Agency. London, 20 January 2010. Committee for MEDICINAL Products for Human Use. Guideline on the Investigation of ioequivalence. http://www.ema.europa.eu/docs/en_GB/document_ library/Scientific_guideline/2010/01/WC500070039.pdf. Accessed November 25, 2010.

8. US Food and Drug Administration. About FDA. Significant Dates in US Food and Drug Law History. http://www.fda.gov/AboutFDA/WhatWeDo/ History/Milestones/ucm128305.htm. Accessed November 25, 2010.

9. US Food and Drug Administration. History of Bioequivalence for Critical Dose Drugs. Gary Buehler, R. Ph. Acting Deputy Director. Office of Pharmaceutical Science. April 13, 2010. http://www.fda. gov/downloads/AdvisoryCommittees/CommitteesMeetingMaterials/ Drugs/AdvisoryCommitteeforPharmaceuticalScienceandClinical Pharmacology/UCM209319.pdf. Accessed November 25,2010.

10. Melethil S. Patent issues in drug development: perspectives of a pharmaceutical scientist-attorney. AAPS J. 2005;7:E723-E728.

11. Levitt GM. The drugs/biologics approval process. In: Pina KR, Pines WL eds. A Practical Guide to Food and Drug Law Regulation 2nd ed. Washington, DC: Food and Drug Law Institute; 2002.

12. Beers DO. Generic and Innovator Drugs: A Guide to FDA Approval Requirements. 5th ed. Frederick, MD: Aspen Publishers; 1999: 3-3,3-24.

13. US Food and Drug Administration. CFR - Code of Federal Regulations Title 21 -Food and Drugs. Chapter I - Food and Drug Administration Department of Health and Human Services Subchapter D - Drugs for Human Use. Part 320. Bioavailability and Bioequivalence Requirements. http://www.accessdata.fda.gov/scripts/cdrh/cfdocs/cfCFR/ CFRSearch.cfm. Accessed November 26, 2010.

14. Chen ML, Shah V, Patnaik R, Adams W, Hussain A, Conner D, et al. Bioavailability and Bioequivalence: An FDA Regulatory Overview. Pharm Res. 2001;18:1645-1650.

15. Guidelines for Bioavailability and Bioequivalence Studies. Central Drugs Standard Control Organization, Directorate General of Health Services, Ministry of Health and Family Welfare, Government of India, New Delhi (March 2005). http://cdsco.nic.in/html/be\%20 guidelines\%20draft $\% 20$ ver10\%20march\%2016,\%2005.pdf. Accessed December 8, 2010.
16. Therapeutic Goods Administration. CPMP Guideline - As adapted in Australia by the TGA - With Amendment - Note for Guidance on the Investigation of Bioavailability and Bioequivalence (CPMP/EWP/QWP/1401/98). Effective 10 April 2002. http:// www.tga.gov.au/docs/pdf/euguide/ewp/140198entga.pdf. Accessed December 8, 2010.

17. Guideline for Bioequivalence Studies of Generic Products (December, 2006). National Institute of Health Sciences. Japan NIHS. http://www. nihs.go.jp/drug/be-guide(e)/be2006e.pdf. Accessed December 8, 2010.

18. Canadian Health Protection Branch (HPB), Health Canada. Guidance for Industry Conduct and Analysis of Bioavailability and Bioequivalence Studies - Part A: Oral Dosage Formulations Used for Systemic Effects. Published by authority of the Minister of Health. 1992. Health Products and Food Branch Guidance Document. http://www.hc-sc. gc.ca/dhp-mps/alt_formats/hpfb-dgpsa/pdf/prodpharma/bio-a-eng.pdf. Accessed December 8, 2010.

19. Asean Guidelines for the Conduct of Bioavailability and Bioequivalence Studies. http://www.suregmp.com/forum/file_down_ok.asp?Folder= PDS\&DownFile=Bioavailabilty_Bioequivalence\%20Studies.pdf. Accessed December 8, 2010.

20. Davit BM, Conner DP, Fabian-Fritsch B, et al. Highly Variable Drugs: Observations from Bioequivalence Data Submitted to the FDA for New Generic Drug Applications. AAPS J. 2008;10(1):148-156.

21. Medicines Control Council. Biostudies. June 2007. http://www.mccza. com/genericDocuments/2.06_Biostudies_Jun07_v2.zip. Accessed December 8, 2010.

22. European Medicines Agency. London, 24 May 2007. Doc. Ref. EMEA/ CHMP/EWP/200943/2007. Committee for Medicinal Products for Human Use (CHMP). Recommendation on the Need for Revision of (CHMP).Note For Guidance on the Investigation of Bioavailability and Bioequivalence. CPMP/EWP/QWP/1401/98. http://www.ema. europa.eu/docs/en_GB/document_library/Scientific_guideline/2009/09/ WC500003009.pdf. Accessed December 8, 2010.

23. European Medicines Agency. Pre-Authorisation Evaluation of Medicines for Human Use London, 24 July 2008. Doc. Ref. CPMP/EWP/ QWP/1401/98 Rev. 1. Committee for Medicinal Products for Human Use (CHMP). Draft. Guideline on the Investigation of Bioequivalence. http://www.ema.europa.eu/docs/en_GB/document_library/Scientific_ guideline/2009/09/WC500003011.pdf. Accessed December 8, 2010.

24. Kingdom of Saudi Arabia Saudi Food and Drug Authority Drug Sector. Bioequivalence Requirements Guidelines. Draft. May 2005. http:/www.sfda.gov.sa/NR/rdonlyres/6A114B70-4201-46EF-B4C7127FD66D3314/0/BioequivalenceRequirementGuidelines.pdf. Accessed December 8, 2010.

25. Guidance Document for Bioequivalence Study of Korea Food and Drug Administration Notification \#2008-22 (May 07, 2008). http:// betest.kfda.go.kr/country/GUIDANCE\%20FOR\%20INDUSTRY\%20 (KFDA_2005).pdf. Accessed December 8, 2010.

26. New Zealand Regulatory Guidelines for Medicines Volume 1. Guidance notes for applicants for consent to distribute new and changed medicines and related products. Fifth Edition. October 2001. http://www.medsafe. govt.nz/downloads/Vol1.doc. Accessed December 8, 2010.

27. Juniper ER, Cockcroft DW, Hargreave FE. Histamine and methacholine inhalation tests: tidal breathing method. Laboratory procedure and standardisation. Astra Draco, Lund, Sweden (1991).

28. Sterk PJ, Fabbri LM, Quanjer PH, et al. Airway responsiveness. Standardized challenge testing with pharmacological, physical and sensitizing stimuli in adults. Official statement of the European Respiratory Society. Eur Respir J. 1993;6(16):53-83.

29. Amidon GL, Lennernas H, Shah VP, Crison JR. A theoretical basis for a biopharmaceutics drug classification: the correlation of in vitro drug product dissolution and in vivo bioavailability. Pharm Res. 1995;12: 413-420.

30. Tamboli AM, Todkar P, Zope P, Sayyad FJ. An overview on bioequivalence: regulatory consideration for generic drug products. $J$ Bioequiv Availab. 2010;2:86-92. 
31. Chinese Pharmacopoeia (2000) Edition 2. Drug bioavailability and bioequivalence testing guidance Principle, Appendix 193-197.

32. Guidance for medication interchangeability of Mexican Official Journal (1999) section I: 45-68.

33. Guidance for Industry. Food-Effect Bioavailability and Fed Bioequivalence Studies, US Department of Health and Human Services Food and Drug Administration Center for Drug Evaluation and Research (CDER), Issued date. December 2002, BP. http://www.fda. gov/downloads/Drugs/GuidanceComplianceRegulatoryInformation/ Guidances/ucm070241.pdf. Accessed December 8, 2010.

34. James CA, Breda M, Baratte S, Casati M, Grassi S, Pellegatta B, et al. Analysis of Drug and Metabolites in tissues and other solid matrices. Chromatogr Suppl. 2004;59:149-156.

35. Midha KK, Rawson MJ, John W. Hubbard. The role of metabolites in bioequivalence. Pharm Res. 2004;21:1331-1344.
36. Henney JE. From the food and drug administration. JAMA. 1999; 282:1995.

37. Rani S, Pargal A. Bioequivalence: An overview of statistical concepts. Indian J Pharmacol. 2004;36:209-216.

38. Westlake WJ. Use of confidence intervals in analysis of comparative bioavailability trials. J Pharm Sci. 1972;61:1340-1341.

39. Schuirmann DJ. A comparison of the two one-sided tests procedure and the power approach for assessing the equivalence of average bioavailability. Pharmacokinet Biopharm. 1987;15:657-680.

40. Haidar SH, Davit B, Chen ML, Conner D, Lee LM, Li QH, et al. Bioequivalence approaches to highly variable drugs and drug products. Pharm Res. 2008;25:237-241.

41. Haidar SH, Makhlouf F, Schuirmann DJ, et al. Evaluation of a scaling approach for the bioequivalence of highly variable drugs. AAPS J. $2008 ; 10(3): 450-454$.
Comparative Effectiveness Research

\section{Publish your work in this journal}

Comparative Effectiveness Research is an international, peer reviewed open access journal focusing on comparative effectiveness of health care including preventative health care strategies, diagnostic strategies, diagnostic technology, medical devices, drugs, medical technology, health systems and organization. The manuscript management system

\section{Dovepress}

is completely online and includes a very quick and fair peer-review system. Visit http://www.dovepress.com/testimonials.php to read real quotes from published authors.

Submit your manuscript here: http://www.dovepress.com/comparative-effectiveness-research-journal 